\title{
Carsharing: the impact of system characteristics on its potential to replace private car trips and reduce car ownership
}

\author{
Fanchao Liao $^{1}$ (D) Eric Molin ${ }^{1} \cdot$ Harry Timmermans $^{2} \cdot$ Bert van Wee $^{1}$
}

Published online: 11 October 2018

(c) The Author(s) 2018

\begin{abstract}
This paper aims to explore the potential of carsharing in replacing private car trips and reducing car ownership and how this is affected by its attributes. To that affect, a stated choice experiment is conducted and the data are analyzed by latent class models in order to incorporate preference heterogeneity. The results show that around $40 \%$ of car drivers indicated that they are willing to replace some of their private car trips by carsharing, and $20 \%$ indicated that they may forego a planned purchase or shed a current car if carsharing becomes available near to them. The results further suggest that people vary significantly with respect to these two stated intentions, and that a higher intention of trip replacement does not necessarily correspond to higher intention of reducing car ownership. Our results also imply that changing the system attributes does not have a substantial impact on people's intention, which suggests that the decision to use carsharing are mainly determined by other factors. Furthermore, deploying electric vehicles in carsharing fleet is preferred to fossil-fuel cars by some segments of the population, while it has no negative impact for other segments.
\end{abstract}

Keywords One-way carsharing · Roundtrip carsharing · Car ownership · Electric vehicle

Fanchao Liao

f.liao@tudelft.nl

Eric Molin

e.j.e.molin@tudelft.nl

Harry Timmermans

H.J.P.Timmermans@tue.nl

Bert van Wee

g.p.vanwee@tudelft.nl

1 Faculty of Technology, Policy and Management, Delft University of Technology, P.O. Box 5015, 2600 GA Delft, The Netherlands

2 Urban Planning Group, Eindhoven University of Technology, P.O. Box 513, 5600 MB Eindhoven, The Netherlands 


\section{Introduction}

Carsharing was introduced a long time ago (its earliest implementation was in the late 1940s) but only gained substantial attention and popularity during the past decade (Becker et al. 2017). Thanks to the widespread use of smartphones, carsharing is becoming increasingly convenient since real time information regarding the availability and location of shared cars can be easily checked via mobile apps. In order to fulfill the diverse demand of consumers, various carsharing schemes are offered in the market, which differ in terms of pricing scheme and ways of organization (one-way vs. roundtrip carsharing). Since carsharing grants people access to cars without the responsibilities and hassles related to car ownership such as regular maintenance and high parking costs, it serves as a viable substitute for conducting car trips and even buying a car for some people. Several empirical studies found that carsharing users reduce their vehicle travel distance and even give up car ownership (Martin et al. 2010; Millard-Ball et al. 2005; Shaheen and Cohen 2013).

The potential of carsharing in reducing car ownership gained considerable attention in automobile industry and policy making. Since each shared car usually can serve more than one person, a carsharing fleet is expected to replace more private cars than the number of shared cars, consequently reducing the total number of cars. Therefore, car manufacturers expect a "reasonable share" of their future profits will be coming from carsharing since car ownership is likely to drop, ${ }^{1}$ and governments are focused on carsharing's potential in relieving the negative externalities brought by both the production and usage of cars, such as pollution, $\mathrm{CO}_{2}$ emission, high parking pressure, etc.

In order for (potential) car owners to switch to carsharing and reduce car ownership, the carsharing scheme has to be able to cover some trips which are currently (or expected) conducted by the private car. Duncan (2011) investigated what kind of car trip patterns can be cost-effectively accommodated by carsharing and derive the potential of joining carsharing by calculating the share of people with the compatible trip pattern. A similar study by Schuster et al. (2005) simulated people's choices between owning private car and carsharing by comparing their costs based on the car condition and trip pattern. However, cost may not be the only consideration and people do not necessarily use carsharing to replace private car trips even if it is slightly cheaper. Furthermore, those who can accommodate more trips by carsharing are not necessarily more willing to reduce car ownership.

In order to decide whether there shall be policy incentives for carsharing, the government needs information regarding the scale of impact of carsharing on car ownership. Moreover, in order to understand how this impact can vary for different carsharing systems and individuals, it is also necessary to know what factors affect people's intentions of private car trip replacement and car ownership reduction. Among all potential influential factors, carsharing system service attributes are especially of interest since they are within the control of service providers.

Of all service attributes, the impact of deploying electric shared vehicle is particularly worth investigating. Many governments have been promoting electric vehicles (EV) due to the sustainability target and EVs have also entered carsharing service. If electric vehicles are deployed in the carsharing fleet, the potential benefits of carsharing are further enhanced. For example, many carsharing users still keep their private car (Martin et al.

\footnotetext{
1 "VW expects profits from car-sharing and ride-hailing", https://www.ft.com/content/29097c88-1bab11e7-a266-12672483791a.
} 
2010) and use carsharing services when their car is not available at the ideal time (e.g. because their partner is using the car), a parking place is too hard to find, etc. In that case, even if those people would not drive less due to carsharing, it can still reduce environmental impacts since most private cars are powered by fossil fuel. Moreover, deploying electric vehicles in shared car fleets provides easier access to electric vehicles (EVs) for many people who still have doubts towards adopting EV as a private vehicle (Zoepf and Keith 2016). People may have less battery-related concerns (replacement costs, life expectancy, possible decrease in range over time) for a shared car compared to a private car they have to purchase, especially if they use shared cars for short urban trips; therefore, a carsharing fleet of EVs may face less resistance from its potential users than the resistance EV has to confront from its potential buyers. From the fleet owners' perspective, EVs may also be a better option because of their lower operational cost and positive environmental image compared to internal combustion engine vehicles. There seems to be a possible synergy of carsharing and electric mobility, therefore it is worthwhile to investigate how deploying electric vehicle would affect potential carsharing users' decision.

The aim of this paper is to investigate the effects of various carsharing system attributes (including car fuel type) on people's choice and propensity of joining and using carsharing. We explore the potential of carsharing in both replacing car trips made by privately owned cars and reducing car ownership. Furthermore, we identify different consumer groups according to their heterogeneous preferences and describe each group based on individualrelated variables. Finally, we explore the relationship between people's intention of using carsharing to replace private car trips and the intention of reducing car ownership. For the above purposes, we conducted a stated choice experiment and applied latent class models to analyze preferences and categorize respondents. This paper contributes to the literature by (1) exploring the impact of carsharing system attributes on the intention of replacing private car trips and reducing car ownership under both roundtrip and one-way carsharing schemes, especially the option of deploying electric vehicles in shared car fleet, (2) identifying different customer groups based on their preferences for carsharing and (3) examining the relationship between car owners' intention of private trip replacement and car ownership reduction.

The remainder of this paper is organized as follows: "Related work" section provides a brief review on relevant literature; "Methodology" section introduces the methodology including survey design, data collection and model estimation. "Results" section elaborates the results we obtained from multiple analyses. The final section provides a discussion regarding the policy implication of the results. Among others, we discuss the implications of our results for the area of shared autonomous vehicles.

\section{Related work}

Most studies on carsharing potential user preferences focus on their decision to enroll as carsharing member, which can be further categorized into three main types. The first type utilizes revealed preference data in the region where carsharing is already available and directly explore the influential factors on people's membership (Becker et al. 2017; Ciari et al. 2015; Juschten et al. 2017). This approach allows the investigation of the impact of those service attributes which differ between carsharing stations or individuals: such as access distance, number of vehicles in each station, etc. (Ciari et al. 2015; Juschten et al. 2017). The second type studies the intention of joining carsharing systems without 
considering other transport options. The dependent variable is the intention to join carsharing, which is then analyzed by regression models to find individual-related variables that significantly influence the intention to join (Efthymiou et al. 2013; Zhou and Kockelman 2011). These studies focus on the impact of individual characteristics on membership decisions. Since they mostly focus on a single given carsharing system, their models do not capture the marginal effects of carsharing system attributes. The third type mainly uses stated choice experiments to study people's choice between joining carsharing and use other transport options. These experiments consist of several choice tasks that vary the attributes of the carsharing system (and of other transport alternatives). This experimental setting allows the preferences for carsharing system attributes to be captured (Kato et al. 2012; Le Vine et al. 2014b). A recent study of this type is Kim et al. (2017a, b) which explores people's choice between joining a carsharing system, buying a second car and remaining the status quo. A context condition worth noticing in this study is that respondents are assumed to own only one car in the household and have limited access to this vehicle when needed (below 60\%) in all choice tasks; however, this may not be the case for many car owners. Despite its valuable contribution, this assumption of a specific context may result in bias when evaluating the general potential of carsharing or even the marginal effects of attributes for the population at large. Besides, this study did not take into account the impact of the fuel type of shared cars. In addition to these three types of studies, (Rotaris and Danielis 2017) applies a rather special approach which uses the generalized cost of carsharing to predict the probability of joining carsharing.

Previous research focusing on the impact of carsharing on car ownership mainly asked current users of carsharing systems to report their (intentions of) ownership change after joining carsharing (Cervero et al. 2007; Firnkorn and Müller 2011, 2015; Kim et al. 2015; Shankar et al. 2015). Le Vine and Polak (2017) also estimated a regression model to see what kind of carsharing users are more likely to reduce their car ownership. The effects are usually expressed by how many private cars have been replaced by shared cars. The estimated number of private cars replaced by each shared car is estimated to vary from 2.5 (Douma and Gaug 2009) to 13 (Martin et al. 2010). However, these studies share some common limitations: first, some studies do not compare the car ownership changes of carsharing members with non-members; second, they focus on current carsharing users who are considered to be the early adopters of the service and their behavior may not be representative of the entire potential user group. Therefore, these numbers are likely to be overoptimistic of the effects of carsharing (Tal 2009), which makes it difficult to extrapolate the results to the total population and estimate the total potential of carsharing on car ownership. As an exception, Klincevicius et al. (2014) used census data to explore the impact of carsharing system on household car ownership.

Few studies investigated what extent carsharing can replace private car trips. An example is Firnkorn and Müller (2011) which asked current car2 $\mathrm{go}^{2}$ users what percentage of current private car trips they plan to replace by car2go, which only provides a descriptive analysis of the intentions of existing users. A much larger share of research investigated people's preferences for carsharing in a short-term mode choice for a given trip, but they only looked at a specific trip context such as commuting (Kim et al. 2017b; de Luca and Di Pace 2014), grocery shopping (Le Vine et al. 2014a) or park and carsharing service

${ }^{2}$ A one-way free-floating carsharing service operated by Daimler. 
(Cartenì et al. 2016); therefore, the results cannot be generalized to assess the total impact of carsharing on replacing private car trips.

Consumer preferences and intentions regarding using carsharing to replace private car trips and reducing car ownership are likely to be heterogeneous since carsharing is a niche market (Bert et al. 2016) and there may only be a certain group of people who will seriously consider carsharing as an option. Most above studies included various individualrelated variables in their models to capture their effects on carsharing decisions intentions, but none have attempted to systematically classify people into groups with different preference profiles. As mentioned in the introduction, our current study aims to address all the above identified research gaps.

Finally, the intention of using carsharing to replace private car trips is usually studied separately from the intention of reducing car ownership. As mentioned in the introduction, some previous studies used "the compatibility of current car trip patterns with carsharing" as a proxy for the possibility of switching away from owning car to joining carsharing (Duncan 2011; Schuster et al. 2005). Another somewhat related study is Le Vine and Polak (2017) which find that among current free-floating carsharing users, those who use the service more often are also more likely to reduce their car ownership. However, to the best of our knowledge, no study attempted to explore whether there is a relationship between the intentions of trip replacement and car ownership reduction.

\section{Methodology}

\section{Data collection and sample}

Since we aim to investigate the impact of carsharing on car ownership, it makes sense to narrow the research subjects down to potential consumers of cars. Therefore, our target population is people who have a driver's license and either own a car or intend to buy a car within the following 3 years. In addition, we only include respondents whose intended purchase is a new car for private use. People who plan to acquire second-hand cars or company cars are excluded because these decisions may involve different considerations (e.g. company car may not be financed by the user).

We used an existing Dutch national panel (Panelclix) to recruit respondents. These panel members fill out questionnaires on a regular basis for a small reward. The members who are invited to participate in our survey are selected at random from the Panelclix list. Those who choose to participate, first answered a series of filter questions and only people who fit our above requirements were asked to finish the entire survey. The data was collected in June 2016 and the final sample consists of 1003 respondents.

Sample characteristics are listed in Table 1. Comparing our sample to the Dutch car owner data, ${ }^{3}$ we can see that our sample is fairly representative regarding employment status and age, while being slightly over-represented by females (due to survey distribution quota aiming to reach gender balance among respondents), and people with relatively low income, which shall be taken into account when interpreting the results.

${ }^{3}$ Only 10 people do not have a car right now. 
Table 1 Sample characteristics

\begin{tabular}{|c|c|c|c|}
\hline Variable & Level & $\begin{array}{l}\text { Percentage in } \\
\text { sample }\end{array}$ & $\begin{array}{l}\text { Percentage in } \\
\text { Dutch car owners }\end{array}$ \\
\hline \multirow[t]{2}{*}{ Gender } & Male & 51.7 & 62.7 \\
\hline & Female & 48.3 & 37.2 \\
\hline \multirow[t]{4}{*}{ Age } & $\leq 35$ years & 25.0 & 18.9 \\
\hline & $36-50$ years & 24.0 & 30.2 \\
\hline & $51-65$ years & 30.8 & 29.8 \\
\hline & $\geq 66$ years & 19.2 & 21.1 \\
\hline \multirow[t]{3}{*}{ Monthly net personal income } & $<1250$ & 17.4 & 8.8 \\
\hline & $1251-2500$ & 49.2 & 28.6 \\
\hline & $>2500$ & 33.4 & 62.5 \\
\hline \multirow[t]{3}{*}{ Employment status } & Paid job & 65.9 & 67.7 \\
\hline & Students & 3.6 & 1.6 \\
\hline & Others & 30.5 & 30.7 \\
\hline \multirow[t]{4}{*}{ Household type ${ }^{a}$} & Single & 16.8 & 22.9 \\
\hline & Couple without children & 40.9 & 35.5 \\
\hline & Couple with children & 31.1 & 37.5 \\
\hline & Others & 11.2 & 4.1 \\
\hline \multirow[t]{2}{*}{ Education level $^{\mathrm{a}}$} & Without high education & 56.6 & 71.1 \\
\hline & With high education & 43.4 & 28.9 \\
\hline \multirow[t]{3}{*}{ Number of cars } & 0 & 1.0 & \\
\hline & 1 & 68.4 & \\
\hline & 2 & 27.6 & \\
\hline \multirow[t]{3}{*}{ Access to own car when needed } & (Almost) always & 86.2 & \\
\hline & Most of the time & 9.5 & \\
\hline & Not more than half & 4.3 & \\
\hline
\end{tabular}

${ }^{a}$ We cannot find data for Dutch car owners regarding this variable. For household type, we used data for the entire Dutch population except children. For education level, we used data for Dutch population above 15 years old

\section{Questionnaire design}

\section{Survey design}

Since we are interested in exploring how individual-related variables affect carsharing preferences and choices, we collected a wide range of information which may be related to decision making of joining and using carsharing. Apart from the basic socio-demographic and socio-economic characteristics, we asked for information related to current car ownership and travel behavior: respondents reported their current state of car ownership and the characteristics of the car they expect to purchase; they were also asked about the frequency of their car trips for each different purpose (including commuting, grocery shopping, other shopping and leisure) and frequency of using public transport and bikes. If the frequency of car trips for a certain purpose is not zero, the respondent is also asked to specify the distance, trip duration and parking time at destination of a typical trip for that purpose. 
In addition, we measured their familiarity and attitudes towards carsharing. We first asked their previous experience with carsharing to see whether they have used, seen or heard of carsharing. In total, $6 \%$ of the respondents are or have been carsharing members. Considering that $1 \%$ of people over 18 years old is estimated to use carsharing in the Netherlands (Harms et al. 2016), carsharing users seem to be overrepresented in our sample, but they still represent a very limited share of all respondents.

In order to measure respondents' attitudes towards carsharing, we presented them with 4 statements about carsharing for which they respond on 5-point Likert scales that runs from (1) totally disagree to (5) totally agree. The seminal work from Bergkvist and Rossiter (2007) showed that if the construct consists of a concrete singular object (in our case being carsharing) and a concrete attribute (attitude for a certain aspect), single items can have the same predictive validity as multiple-item measurements; therefore we can still use it even if the reliability is lower. Taking this into account, in order to capture the attitude of multiple aspects with the least number of statements, the four statements are meant to cover aspects of attitude different from each other.

Table 2 presents the four statements and the distribution of their responses. In general, carsharing does not have a negative image and people do recognize the environmental friendliness of carsharing; however, on average people do not appreciate the convenience brought by carsharing and still have a relatively strong attachment to car ownership. Two statements are found to have high communalities; therefore, we generated a factor "hedonic attitude" from these two statements. The other two statements measure the symbolic and environmental attitude respectively. All factor and item scores are standardized for further use.

\section{Choice experiment design}

The main part of the survey is a stated choice experiment which focuses on the decision regarding the frequency of using carsharing and car ownership. As we mentioned in the introduction, carsharing schemes can be categorized into two types, namely roundtrip and one-way. The two most crucial differences between these two types are the following. First, for roundtrip carsharing the shared car always has to be returned to its pick-up point while this is not required for one-way carsharing; Second, roundtrip carsharing allows advanced booking while one-way carsharing does not (booking time up to $30 \mathrm{~min}$ ). We decide to not include both systems in the same choice task since we do not aim to study the competition between roundtrip and one-way carsharing systems; besides, for those respondents who are not that familiar with carsharing, learning about both schemes and trading off between them is rather difficult and may lead to more misunderstanding and errors. Therefore, a separate experiment was constructed for each scheme, and respondents were randomly assigned to only one of the experiments. Before the start of the experiment, respondents were introduced to the basic characteristics of the respective carsharing scheme.

In each choice task, respondents were asked to make a choice between two given alternatives which are a car and a carsharing scheme. The presentation of the car alternative differs depending on the respondents' condition: people who intend to purchase a car in the near future (from now on referred to as prospective car buyers) were presented with a car alternative of which the attributes describe the car they expect to purchase. This information is collected from their answers to previous questions in the questionnaire. They were asked whether they are willing to forego the car purchase and use the given carsharing scheme instead. Other respondents (referred to as car holders) were only presented the 
Table 2 Statements used for attitude measurement and their responses

\begin{tabular}{lllll}
\hline $\begin{array}{l}\text { Cat- } \\
\text { egory }\end{array}$ & Statement & Average score & SD & Factor loading \\
\hline $\begin{array}{l}\text { Sym- } \\
\text { bolic }\end{array}$ & Carsharing is for people who cannot afford cars & 2.64 & 0.834 & \\
$\begin{array}{l}\text { Environ- } \\
\text { mental } \quad \begin{array}{c}\text { Carsharing is more environmentally friendly } \\
\text { than buying a car }\end{array}\end{array}$ & 3.46 & 0.850 & 0.816 & 0.617 \\
$\begin{array}{l}\text { Hedonic } \quad \begin{array}{l}\text { Carsharing causes more problems than owning } \\
\text { a car }\end{array} \\
\quad \begin{array}{l}\text { I like the feeling of owning a car and carsharing } \\
\text { cannot match that }\end{array}\end{array}$ & 3.71 & 0.874 & 0.617 \\
\hline
\end{tabular}

attributes of a carsharing scheme and answer whether they are willing to sign up for the presented carsharing scheme and give up a car which they currently own. At the end of the experiment, these car holders filled in the characteristics of their own car (or if they have more than one car, the car which they are most likely to give up) and we assume that this is the car with which they traded off in all choice tasks.

Table 3 lists the attributes that are varied in the experiment and their levels. In the experiment for prospective car buyers, the attribute values of the expected car purchase are based on the answers provided by respondents and fixed in all choice sets presented to the respondent. The attributes for carsharing schemes are all varied by three levels except the return location of one-way carsharing, their operationalization is further elaborated below:

- Fuel type of car This attribute is varied in the levels: (1) gasoline car, (2) electric car with $100 \mathrm{~km}$ of driving range and (3) electric car with $200 \mathrm{~km}$ of range after full charge. This allows investigating preference between gasoline vehicle and electric vehicle with short and medium driving ranges.

- Purchasing cost: In case of roundtrip carsharing we set a deposit which is fully refunded after the membership expires, while for one-way carsharing we specify a one-time registration fee. This setting fits the current situation of existing carsharing schemes in the Netherlands.

- Maintenance cost A monthly membership fee is also specified for both carsharing schemes. The values for one-way carsharing are lower than that of roundtrip because current one-way carsharing (such as car2go) do not charge any monthly fee while it is common among roundtrip carsharing schemes.

- Operating cost The structures and levels of operating cost attributes of both carsharing alternatives are based on the price levels of current carsharing schemes in the Netherlands.

- Access time to the shared car is also included as an attribute: since the position of shared cars is not fixed at each time of use, the respondents are told that this is an average value.

- Car availability With respect to this attribute we use two different measures for the two carsharing schemes based on their different booking mechanism. Since for roundtrip carsharing it is possible to book a time slot in advance and check when cars are available, the measure we use is the difference between the initial ideal departure time and the closest time slot available. For example, a "15 min difference from ideal time" implies that on average a shared car is available only 15 min earlier or later than the 


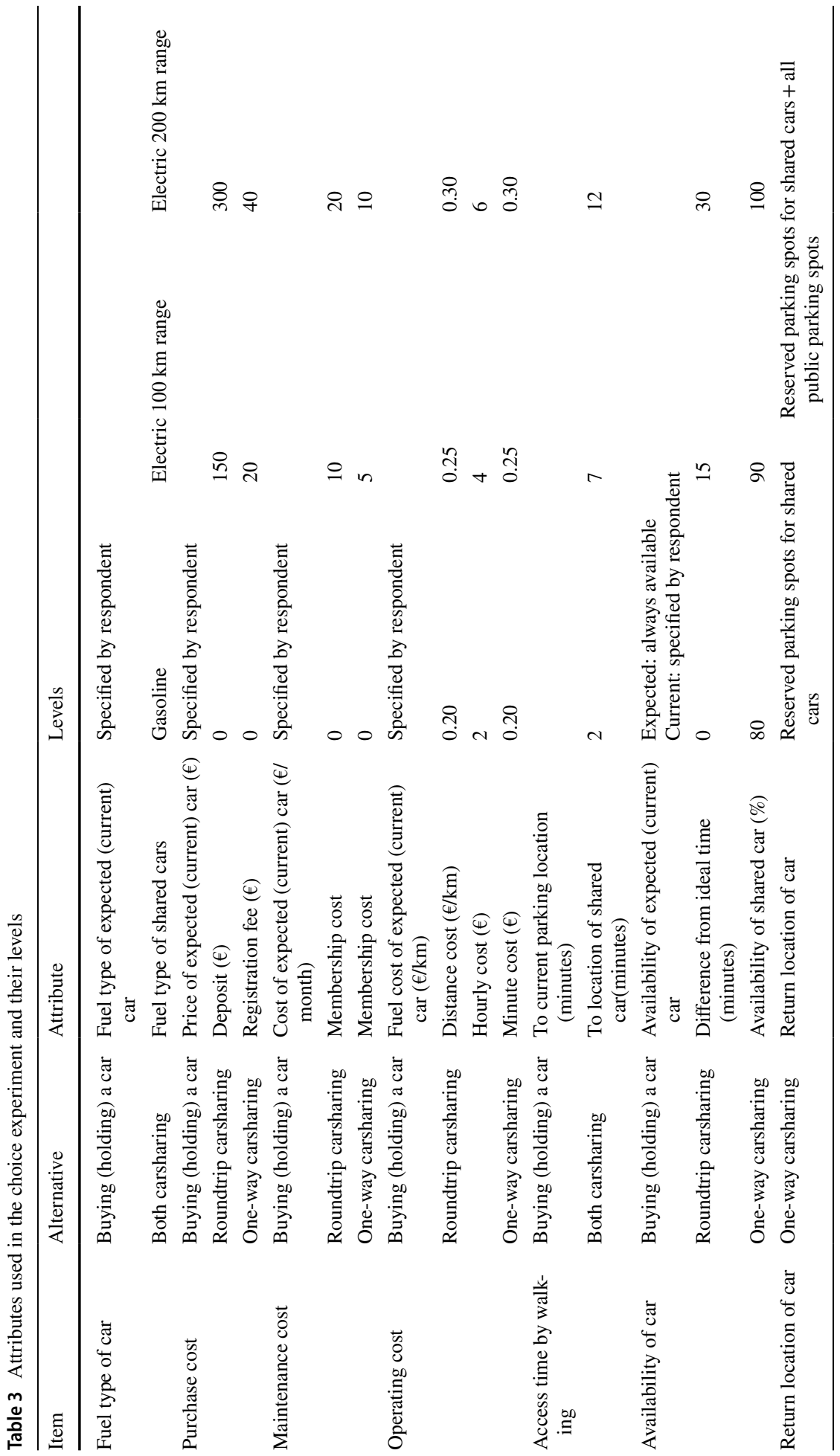


initial ideal departure time. We only give the average value in order to control the complexity of the experiment. Since one-way carsharing does not allow booking and one can hardly do anything when no car is available (within reasonable walking distance), its availability measure is straightforwardly defined as the probability of a shared car appearing to be able to use when needed.

- Return location of car This attribute only applies to one-way carsharing. It has two levels: (1) reserved parking spots for shared cars: this corresponds to one-way stations-based carsharing for which users have to park the car in the designated spots; (2) reserved parking spots for shared cars + all public parking spots: this level represents free-floating carsharing, which allows users to park the car anywhere allowed.

In addition to exploring to what extent carsharing can reduce car ownership, we were interested in exploring the potential of carsharing in reducing trips which would otherwise be done by private fossil fuel cars. To that effect, respondents were asked to indicate for each car sharing alternative to what extent they use it to replace their car trips (about which we posed questions earlier in the survey). An answer was given for each of the four different trip purposes using a 5-point scale ranging from 1 "never" to 5 "for all trips". An example of a choice task and questions is shown in Fig. 1.

Both choice experiments were created using a D-efficient optimal design (Rose and Bliemer 2009). The priors are mostly based on findings of previous research (Kim et al. 2017a) and assumed when not available. With this input, we used Ngene to construct the two choice experiments and ended up with a 12-choice set design for each, which was blocked into 2 blocks each with 6 tasks to which a respondent was randomly assigned. Hence, every respondent faced 6 choice tasks. In the end, the one-way carsharing experiment had 521 respondents in total while the roundtrip experiment received 482 responses.

\section{Model conceptualization}

Corresponding to the two questions in each choice task, we have two dependent variables. The first is an ordinal one measuring the extent to which the respondent is willing to replace private car trips by carsharing. Although in each choice task we collect responses for up to ${ }^{4}$ four common trips of different purpose (commuting, grocery shopping, other shopping and leisure), we assume that all influential factors have the same effect on these four responses and use a single model to describe these effects. The second variable is dichotomous and denotes the choice whether to proceed with a planned car purchase (or between keeping or shedding the current car). These two dependent variables are indicators for the latent utility of each level of replacement intensity or each choice.

Regarding the trip replacement intensity, we explore how its utility is determined by the attributes of both the carsharing system and own car. We have already elaborated upon the carsharing system attributes in "Questionnaire design" section. The own car attributes we concern are fuel costs and walking distance to the parking location. Utility is also expected to be dependent on the trip characteristics as carsharing may be more feasible and suitable for some trips than others. The characteristics we

\footnotetext{
${ }^{4}$ If the respondent previously indicated that s/he never conducts or does not use a car to conduct a certain type of trip, no response is collected for this trip.
} 
investigated include trip frequency, duration, staying time at location and the purpose of trip.

As for the choice of car ownership, the utility of choosing carsharing is also assumed to be dependent on the attributes of carsharing system and own car. Although more own car attributes are expected to be influential in this decision: apart from fuel cost and distance to parking location, we also explore the effect of car price, monthly maintenance cost and availability of own car.

The effects of these attributes and factors on utility are expected to be heterogeneous among people. Therefore, we assume that the entire population consists of several classes: these effects are homogeneous within each class and vary between different classes.

Finally, we are also interested in the role individual variables play in determining class membership. In addition to the common socio-economic and socio-demographic variables, we also investigated the influence of frequency of using bikes and public transport and attitudes towards carsharing. Figure 2 is an illustration of the conceptual models for both trip replacement and car ownership.

\section{Model specification}

We applied latent class models to implement the above conceptualization. To be more specific, we estimated a latent class ordinal regression model for modelling trip replacement and a latent class choice model for the car ownership model.

Let $y_{i t}$ denote the response of respondent $i$ in choice task $t$ and $m$ represent a specific category of all possible responses. In the case of trip replacement intensity, $m$ can range from never (1) to all (5). In the case of car ownership choice, the respondent can choose either car purchase or carsharing, therefore $m$ can take two values. The final stated responses $y_{i t}$ are indicators of $\eta_{m \mid z_{i t}}$ which indicates the latent systematic utility of each category (trip replacement intensity) or alternative (car choice) of the response variable for subject $i$ in choice task $t$.

In car ownership model, the value of this latent utility has the following form:

$$
\eta_{m \mid z_{i t}}=\beta_{m}+\sum_{k=1}^{K} \beta_{m k} z_{i t m k}^{a t t}+\varepsilon
$$

in which $\beta_{m}$ and $\beta_{m k}$ denote the alternative-specific constant and attribute effects respectively. $z_{i t m k}^{\text {att }}$ represents the value of attribute $k$ of alternative $m$ in choice task $t$ for subject $i$. In latent class models, the entire sample population is assumed to belong to $K$ different latent classes which differ in their taste parameters. Therefore, the utility function of members from class $\mathrm{x}$ is

$$
\eta_{m \mid x, z_{i t}}=\beta_{x m}+\sum_{k=1}^{K} \beta_{x m k} z_{i t m k}^{a t t}+\varepsilon
$$

which implies that a different set of $\beta_{m}$ and $\beta_{m k}$ will be estimated for each class $x$. The conditional probability for the response follows the multinomial logit function:

$$
P\left(y_{i t}=m \mid x, z_{i t}\right)=\frac{\exp \left(\eta_{m \mid x, z_{i t}}\right)}{\sum_{m^{\prime}=1}^{M} \exp \left(\eta_{m^{\prime} \mid x, z_{i t}}\right)}
$$




\begin{tabular}{|c|c|c|}
\hline & Buying a car & Roundtrip carsharing \\
\hline Fuel type of the car & Gasoline & $\begin{array}{l}\text { Electric vehicle with } 200 \mathrm{~km} \\
\text { range }\end{array}$ \\
\hline Purchase cost & Price of car: $€ 24000$ & $\begin{array}{l}\text { Deposit: } € 300 \\
\text { Fully reimbursed after the } \\
\text { membership expires }\end{array}$ \\
\hline Monthly maintenance cost & $\begin{array}{c}€ 250 \\
\text { Insurance, repairs, taxes }\end{array}$ & Membership cost: $€ 10$ \\
\hline Operating cost & Fuel cost: $€ 0.13 / \mathrm{km}$ & $\begin{array}{l}€ 0.20 / \mathrm{km} \\
+€ 4 / \mathrm{hr}\end{array}$ \\
\hline Car availability & Alway available & $\begin{array}{l}\text { Available } 15 \text { minutes before or } \\
\text { after the ideal booking time }\end{array}$ \\
\hline Access time & 2 minutes & 4 minutes \\
\hline
\end{tabular}

1. If this carsharing scheme is available in your neighbourhood, to what extent will you use it for the car trips of the following purposes?

\begin{tabular}{|c|c|c|c|c|c|}
\hline & None & For a few trips & $\begin{array}{c}\text { For around } \\
\text { half }\end{array}$ & For most trips & For all trips \\
\hline Work/school & $\bullet$ & 0 & 0 & 0 & 0 \\
\hline Grocery shopping & $\bullet$ & \multicolumn{4}{|c|}{ I never make this trip by car } \\
\hline $\begin{array}{l}\text { Shopping (appliances, } \\
\text { clothes, etc.) }\end{array}$ & $\bullet$ & $\odot$ & 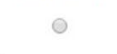 & $\odot$ & $\odot$ \\
\hline $\begin{array}{l}\text { Leisure(visitng family and } \\
\text { friends, recreation, etc.) }\end{array}$ & $\bullet$ & 0 & 0 & 0 & 0 \\
\hline
\end{tabular}

2. If this carsharing system is available in your neighbourhood, will you still make the planned car purchase?

Fig. 1 An example of stated choice task (text translated from Dutch)

In the trip replacement model, the dependent variable is of ordinal level and the response probability function is exactly the same as (3) while the "utility" function becomes

$$
\eta_{m \mid x, z_{i t}}=\beta_{x m 0}+\sum_{q=1}^{Q} m \beta_{x q} z_{i t q}^{p r e d}
$$

which applies the function of an adjacent-categories ordinal logit model (Agresti 2002). $z_{i t q}^{p r e d}$ denotes the explanatory exogenous factor $q$ which differs between choice tasks. These factors are usually termed as "predictors" in latent class regression models. $\beta_{x m 0}$ and $\beta_{x q}$ are class-specific intercepts of level $m$ and effects of predictor $q$ on utility which need to be estimated.

For each subject $i$, the probability of belonging to a class $\mathrm{x}$ is predicted by its individual characteristics $z_{i}^{c o v}$ which are termed "covariates". This probability function also takes the form of a multinomial logit model:

$$
P\left(x \mid z_{i}^{c o v}\right)=\frac{\exp \left(\gamma_{x 0}+\sum_{r=1}^{R} \gamma_{x r} z_{i r}^{c o v}\right)}{\sum_{x^{\prime}=1}^{S} \exp \left(\gamma_{x^{\prime} 0}+\sum_{r=1}^{R} \gamma_{x^{\prime} r} z_{i r}^{c o v}\right)}
$$

Hence, for each class an intercept $\left(\gamma_{x 0}\right)$ and a set of regression coefficients $\left(\gamma_{x r}\right)$ are estimated. However, some individual-specific variables are dependent on other common covariates (such as socio-economic characteristics) and thus cannot be considered as "truly independent"; in contrast to the active covariates, these variables can be included as "inactive" covariates. The name implies that these covariates do not affect the probability of 


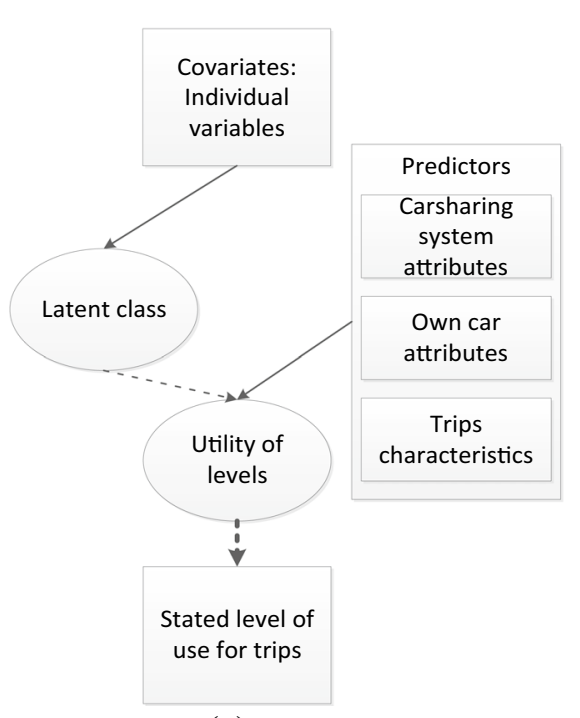

(a)

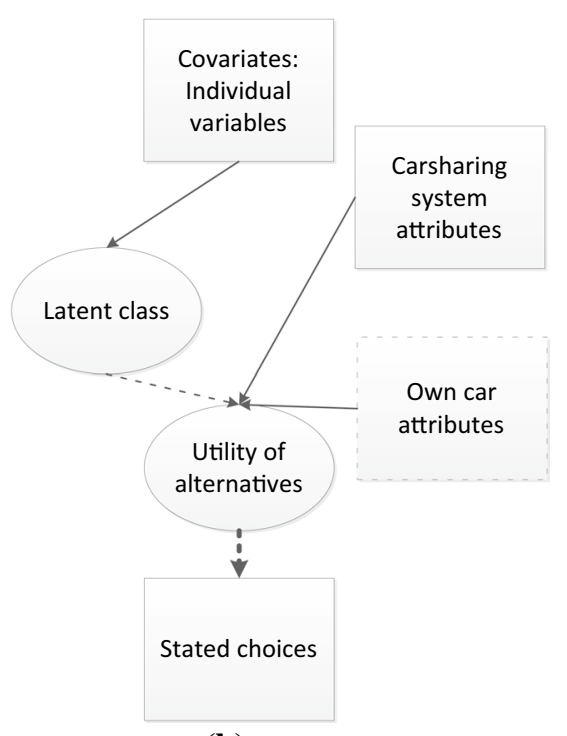

(b)

Fig. 2 Model conceptualization: a trip replacement model; $\mathbf{b}$ car ownership model

class membership and are not included in the model estimation. Instead, we calculate the distribution of inactive covariates for each class, which provides a richer profile of different classes. In this study, urban density is included as an inactive covariate.

Finally, the probability of observing a certain sequence of responses can be written as

$$
P\left(\boldsymbol{y}_{i}\right)=\sum_{x=1}^{S} P\left(x \mid z_{i}^{c o v}\right) \prod_{t=1}^{T} P\left(y_{i t}=m \mid x, z_{i t}\right)
$$

\section{Model estimation}

The latent class regression and the latent class choice model were each estimated separately for one-way and roundtrip carsharing, hence, four models were estimated in total. For the trip replacement model, we pooled and stacked the responses for each of the four trips with different purpose in one dataset in order to estimate a single model for all trips as we mentioned in conceptualization.

We used LatentGold (Vermunt and Magidson 2013) to estimate all four models. Effects coding was used for all parameters of categorical variables. We used several criteria in order to determine the optimal number of classes: first, statistical measures including $\rho 2$ values and the Bayesian Information Criterion (BIC), which take both model quality and parsimony into account; second, the interpretability of the estimated model, such as the sign and size of coefficients; third, avoid solutions with classes which are not essentially different from other classes; According to all the above criteria, for the latent class ordinal regression model of trip replacement, we arrived at a 3-class structure; and we chose the 2-class solution for the latent class discrete choice model of car ownership. 


\section{Results}

This section elaborates the results from the estimated models. We first consecutively present the results of the trip replacement model and the car ownership model; in the end, we discuss the connection between these two choices.

\section{Trip replacement model}

\section{Consumer groups and preference heterogeneity}

Based on their different preferences regarding the frequency of replacing private car trips by carsharing, both in the model for one-way car sharing and the model for roundtrip car sharing, the respondents can be categorized into three classes. Table 4 lists the result of these two latent regression models. Both model fits are quite high and the pseudo R square is significantly improved compared to the one-class ordinal regression model, which demonstrates the power of the latent class model; the prevalence of non-trading behavior (see below for a detailed description) can also be a reason for the high model fit.

We first briefly characterize each of the classes based on their indicated frequency of use as presented in the top of Table 5. Class 1 demonstrates an extremely low interest in using car sharing both under one-way and roundtrip car sharing, which can be labeled as "own car oriented". When answering the questions about the share of their car trips they intend to replace by carsharing, they choose the category 'none' for $95 \%$ of the time. In contrast, Class 2 intends to replace a larger share of their trips by carsharing and can be described as "CS-leaning". Class 2 under roundtrip carsharing intends to replace more trips than the same class under one-way car sharing. Finally, Class 3 intends to use carsharing the most for replacing their car trips. They are likely to be frequent users for carsharing and are termed "CS-enthusiasts". Their responses lean more towards the extremes under roundtrip carsharing; in other words, there are more responses for categories 'none', 'most trips' and 'always'. This suggests that in case of roundtrip carsharing, the responses of Class 3 are more divergent across different rating tasks, which implies that the choices are more sensitive to changes in carsharing system attributes and/or different trip characteristics.

As for the size distribution between the three groups, Class 1 is bigger under roundtrip carsharing (63.4\%) than under one-way (54.7\%), which implies that the latter seems to be capable of attracting more subscribers. Class 3 under one-way carsharing (20.5\%) also takes a larger share than under roundtrip (13.9\%).

Next, we describe how the trip replacement decisions of the three classes are differently affected by carsharing system attributes, trip characteristics and their current car characteristics. First, we focus on carsharing system attributes. The preference for vehicle type significantly varies across the three groups. For both roundtrip and one-way carsharing, Class 1 prefers gasoline cars, while Class 3 does not have a significant preference over car types used in carsharing systems. Class 2 prefers gasoline vehicles to EVs with only $100 \mathrm{~km}$ of driving range under one-way carsharing. However, EVs with $200 \mathrm{~km}$ range is even slightly preferred to gasoline vehicles, suggesting that a driving range of $200 \mathrm{~km}$ is sufficient to meet consumer's needs. Under roundtrip carsharing, Class 2 even prefers EVs with $100 \mathrm{~km}$ range to gasoline vehicles. 
The taste parameters for the carsharing attributes costs, availability and access time also differ across the three groups. For Class 1, all parameters have the expected sign and most are statistically significant at a $95 \%$ confidence level both under one-way and roundtrip carsharing. On the other hand, for both Class 2 and 3, only registration cost or access time to shared car have a significant impact. It is worth noticing that the coefficient for flexible return location of one-way carsharing is non-significant for all classes, which implies that whether the one-way carsharing system is station-based or free-floating does not seem to influence people's trip replacement decisions. The prevalence of non-significance is probably due to the rather small size of these two predicted classes (especially class 3 ). Another possible reason is that most system attributes genuinely do not have much impact on trip replacement decisions of these two classes, at least not if the attribute values lie within the range of levels varied in the choice experiment.

Two coefficients for Class 3 which are statistically significant have unexpected signs, namely the membership cost of one-way carsharing and the distance cost of roundtrip carsharing; their size is however rather small in comparison to the constants and other attributes. A possible reason is that a small number of people associate low cost to low quality (we did not specify the quality of the shared cars), despite the fact that we ask respondents to assume the carsharing systems in the experiment are identical apart from the attributes we describe. Since Class 3 is rather insensitive towards costs (all other cost attributes are non-significant), these people may prefer a higher quality system. Hence, they may think it is represented by high cost, which may explain the positive cost parameter. In general, the parameter estimates of Class 3 in our model are not conclusive and shall not be overly interpreted since the predicted class size is small. If we wish to obtain accurate parameter values for this class, it is advisable to collect a larger sample or over-recruit people who have strong intention to replace private car trips by carsharing.

Trip characteristics, including trip purpose, frequency, duration and staying time at destination all influence the trip replacement decisions. Under one-way carsharing, their impacts are vastly different between Class 2 and 3. Class 3 tends to use carsharing more to replace trips which are more frequent, less than $1 \mathrm{~h}$ and require a longer stay at the destination, while this is the opposite for Class 2 . Furthermore, Class 3 mostly tends replace more grocery shopping trips, while Class 2 is willing to replace more shopping and leisure trips. Under roundtrip carsharing, both Class 2 and 3 tend to replace more trips which last between 16 and 30 min and when the stay at the destination is less than an hour. Class 2 also replaces more frequent trips while there is no clear preference for Class 3 .

It is worth mentioning that the parameter estimates cannot be directly contrasted with the normal usage pattern of current carsharing systems. For example, a typical roundtrip carsharing trip mostly has a parking time around $3 \mathrm{~h}$; while our model shows that Class 3 prefer parking time of less than $1 \mathrm{~h}$ the most, which may seem contradictory. However, the parameter estimates are class-specific and relative, while the revealed pattern is also related to the distribution of trip characteristics among the population. Parking time between 2 and $4 \mathrm{~h}$ is not significantly preferred by Class 3, but Class 3 members conduct significantly more trips with $2-4 \mathrm{~h}$ parking time (compared to trips with other parking duration), therefore this may still end up with a peak pattern of 3-h parking time even if there is no relative preference between trips with different parking time. In addition, each trip's utility score is a combination of the coefficients of all its characteristics (duration, frequency, etc.). Most of these trips also have a trip duration of less than 5 min which has a large negative coefficient, therefore these trips turn out to be less preferred.

The characteristics of the current car also have a significant impact on the intensity of trip replacement. As expected, under both one-way and roundtrip carsharing, most groups 


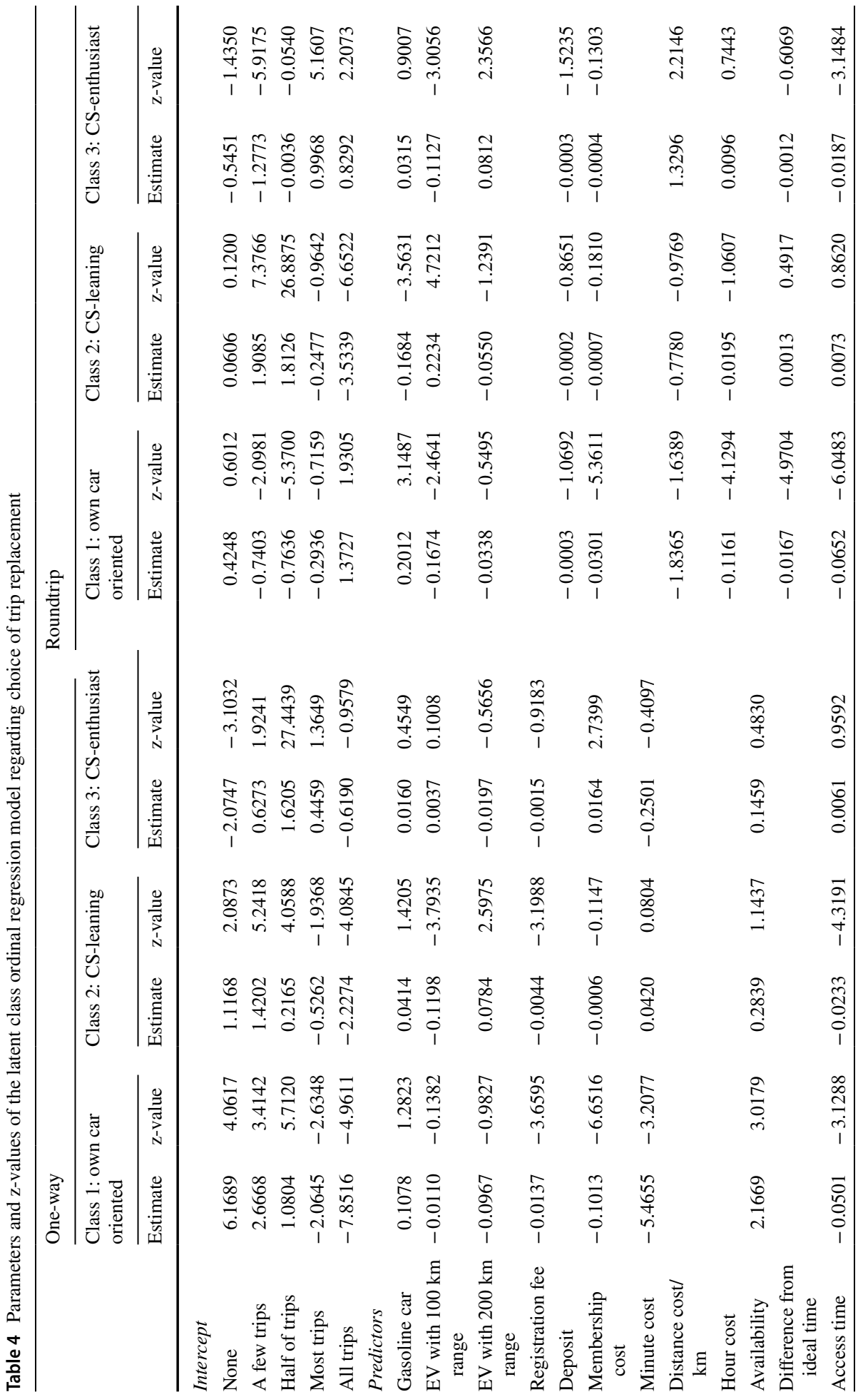




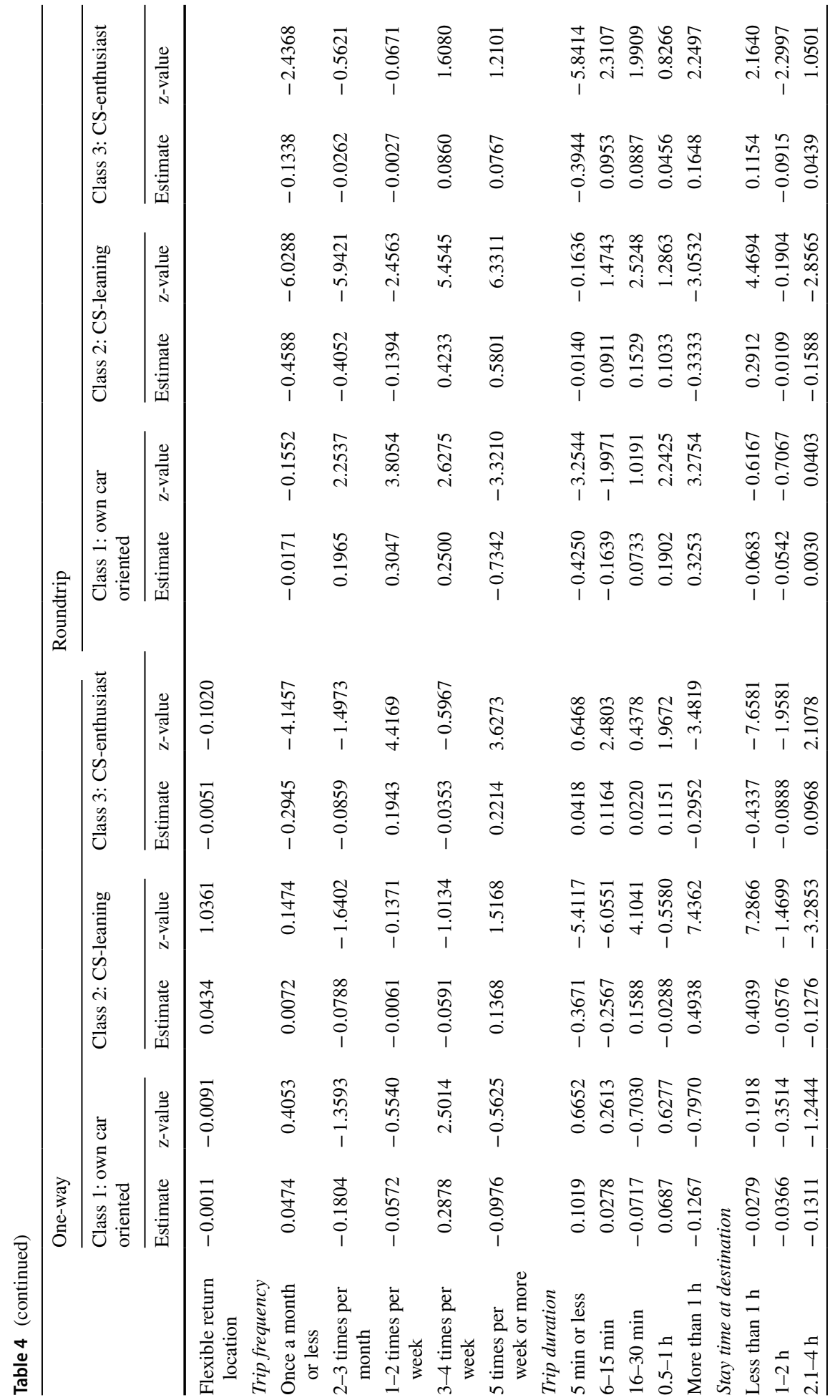




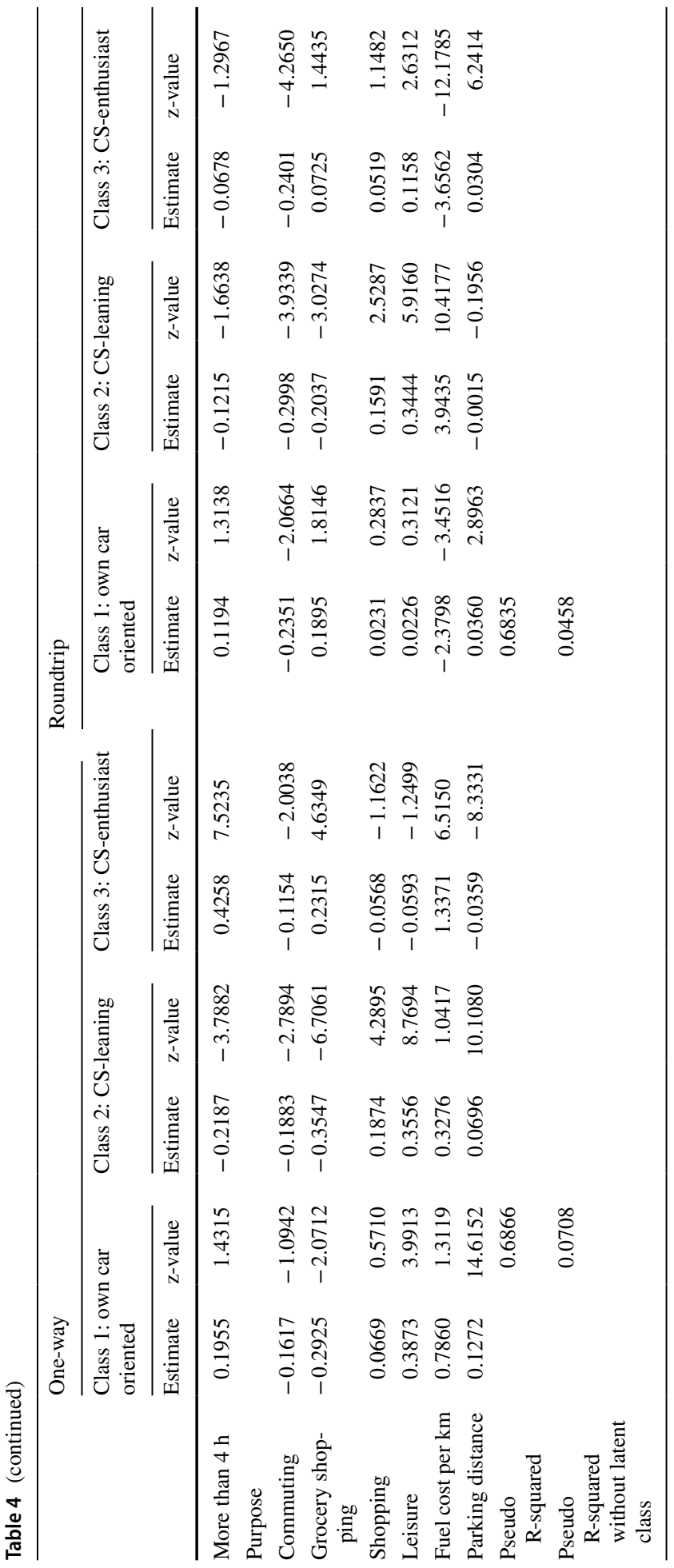




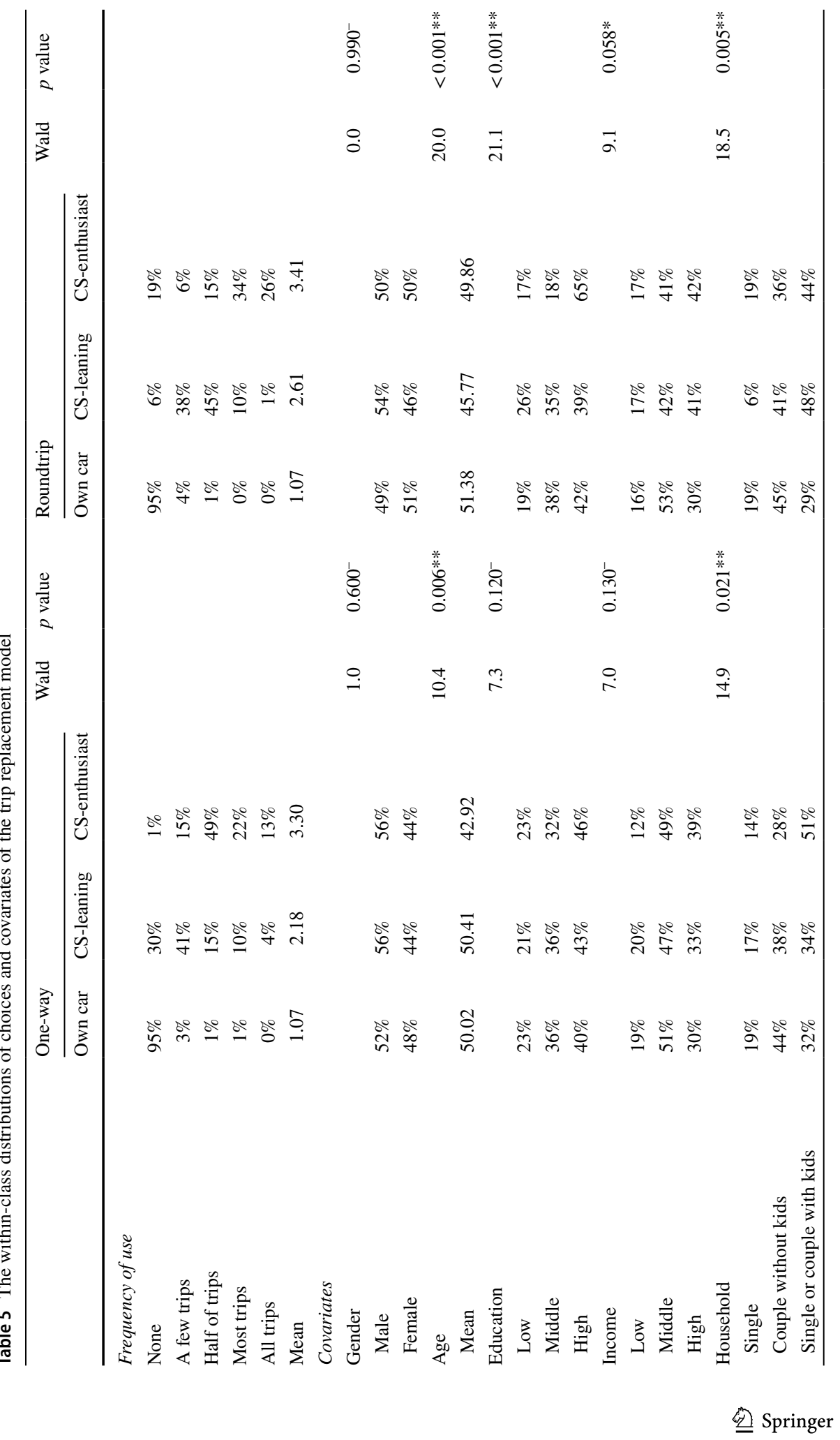




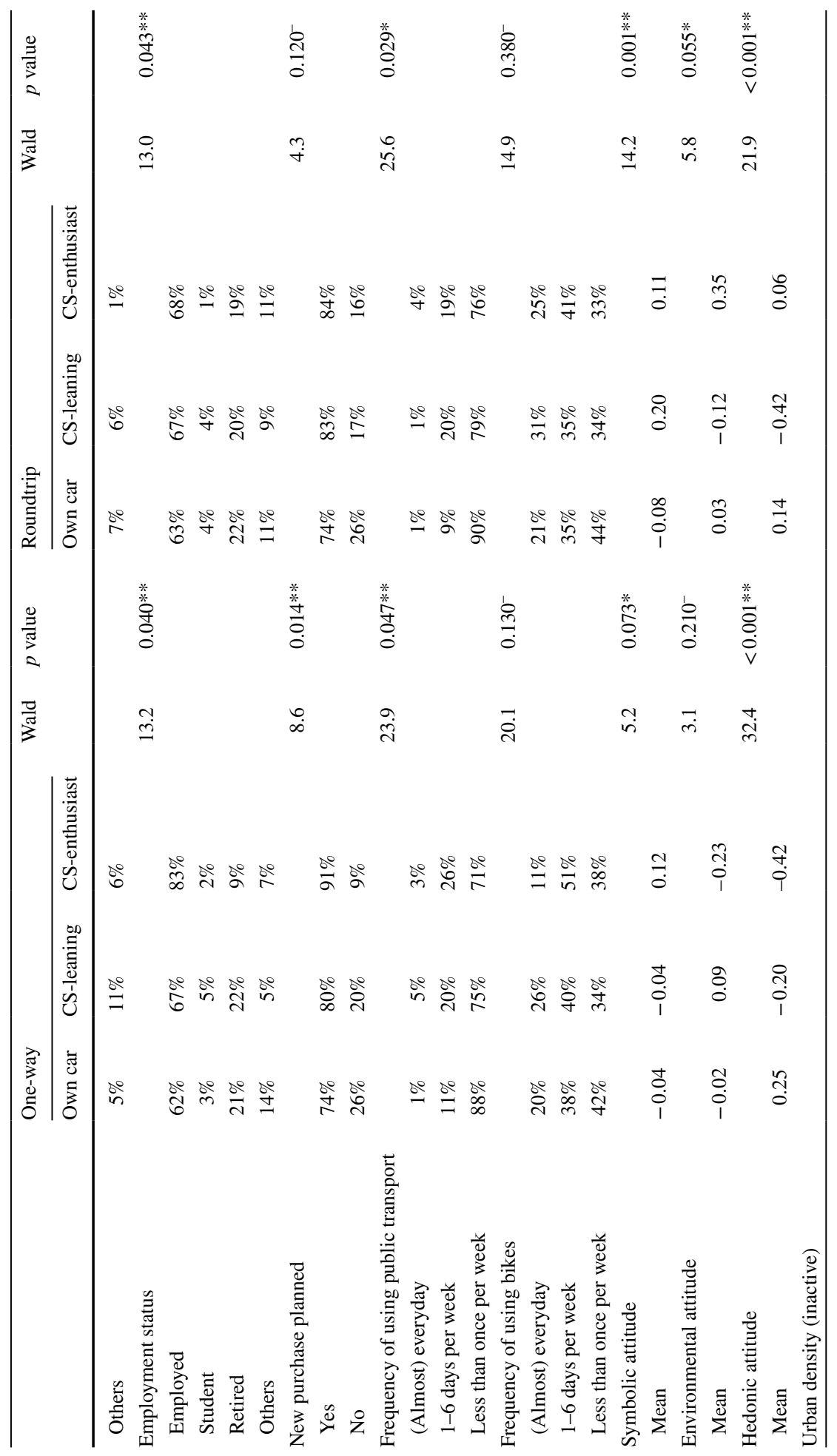




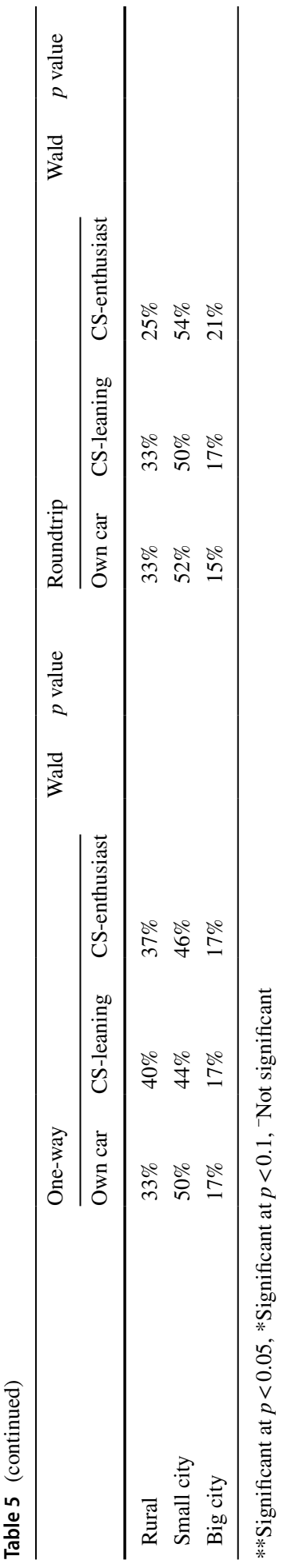


tend to use carsharing more to replace their car trips if they currently (or are expected to) have higher fuel cost or a longer parking distance.

\section{Personal characteristics}

The class membership model reveals the impact of personal characteristics on class membership. Table 5 displays the individual variables included in the model and their Wald statistics and $p$ value. The within-class percentage distribution of each individual covariate is also presented.

Class 3 has the largest share of people who are younger, highly educated, earning high income, employed, have kids and use public transport more often under both one-way and roundtrip carsharing (a couple of effects are not statistically significant though). By contrast, the composition of Class 1 is mostly opposite to Class 3 in terms of these individual characteristics. In other words, the covariate distribution of Class 1 and 3 lie on different ends of the spectrum. For example, with respect to employment status, Class 3 have the highest percentage of employed people while Class 1 have the lowest. Consequently, the covariate distribution of the Class 2 mostly lies between Class 1 and 3. The only exceptions are age and educational level: under roundtrip carsharing Class 2 is the youngest and least educated; on the other hand, under one-way carsharing it is the oldest. There is no significant difference in the distribution of gender and urban density across the three groups.

Since Class 2 and 3 indicate their intention to use carsharing and are likely to enroll for carsharing membership, we can contrast their characteristics to the previous findings in carsharing members. We confirm the typical image of CS users: younger than average, well-educated, have higher income, employed and more likely to have children (Becker et al. 2017; Le Vine and Polak 2017). Becker et al. (2017) also found that people who are employed tend to use one-way carsharing more frequently: although there is no discernible different between Class 2 and 3 regarding the employment status for roundtrip carsharing, we do find that under one-way carsharing Class 3 has a much higher percentage of employed people than Class 2. Finally, while most studies find carsharing members are predominantly male (Becker et al. 2017; Juschten et al. 2017 and its citations), we do not find any significant impact of gender on the intention of trip replacement.

We now focus on the impact of attitude on class membership. All three attitudes have a significant influence in case of roundtrip carsharing, while only symbolic and hedonic attitude are relevant under one-way carsharing. Surprisingly, the average attitude is not always congruent with the preferences of every group. In the model of one-way carsharing, while Class 3 has the highest preference for carsharing, they attach a more negative symbolic value to carsharing compared to the other two groups. This counter-intuitive result suggests that this negative connotation is not strong enough to deter Class 3 away from using carsharing. Under roundtrip carsharing, Class 2 recognizes the environmental-friendliness of carsharing the least while they intend to replace more trips than Class 1, which suggests that the replacement is not motivated by environmental considerations.

\section{Discussion}

The impact of carsharing system attributes on the intended frequency of private car trip replacement is rather limited according to our model. For Class 1, although all coefficients are significant, group members choose to never use carsharing to replace their private car trips in $95 \%$ of their responses to trip replacement questions. Therefore, the effect of 
promoting carsharing usage is expected to be rather limited for this class if the performance of carsharing systems is not drastically increased (beyond the range we tested). For the other two classes, only shared car type, registration cost and average access time to shared car are significant predictors. A previous study based on an existing carsharing system also finds that the distance to carsharing stations is a significant determinant of carsharing membership (Juschten et al. 2017). In general, most attributes regarding costs and availability of car do not have a significant impact on trip replacement decisions.

We mentioned above that the preference for car type differs for Class 2 in two schemes: for one-way carsharing EV with $200 \mathrm{~km}$ range is their favorite, while for roundtrip carsharing EV with only $100 \mathrm{~km}$ range is already preferred over gasoline vehicle. This may be explained by the characteristics of the trips for which they prefer to use carsharing. Under roundtrip carsharing, Class 2 uses it more for trips of middle length (16-30 min), for which $100 \mathrm{~km}$ range is less likely to be a problem; on the other hand, they use it mostly for longer (more than $1 \mathrm{~h}$ ) trips under one-way carsharing and $200 \mathrm{~km}$ seems to be sufficient to meet their requirements.

Different classes also vary in terms of their attitudes towards carsharing and how their own car characteristics affects their willingness to use carsharing in replacement of private car. These coefficients may reveal the respondents' motivation of using carsharing. For example, under one-way carsharing, Class 2 members who currently have higher fuel costs intend to use carsharing to replace more trips, which is probably motivated by saving operation cost of car trips.

Apart from the socio-demographic variables and attitudes, we also examined the trip patterns of each class in order to explore whether those who show higher intention have a trip pattern more "compatible" with carsharing. The trip characteristic distributions of all classes are almost identical. For roundtrip carsharing, Class 3 only stands out with the highest share of trips with parking time between 2 and 4 h (29.4\% vs. average of $26.4 \%)$, which matches the typical trip pattern of each carsharing system. Class 3 of one-way carsharing has the highest share of frequent trips (at least 3 times per week, $33.5 \%$ vs. average of $24.5 \%$ ), this demonstrates that the flexibility of one-way carsharing makes them more suitable for accommodating frequent trips such as commuting. In general, it seems that Class 3 does not have any distinct trip pattern which can explain their high intention of trip replacement.

\section{Car ownership model}

This section looks at people's choice regarding whether they will use carsharing to replace their expected car purchase or current car. Table 6 presents the estimated choice model and Table 7 presents the distributions of covariates within each class. We found that a two-class model structure best describes the behavior. We first estimate a full model, and in the final model we constrain those parameters which are not significantly different across classes to be equal. The final model fit is high and the improvement from basic multinomial logit model is also significant. However, since most attributes are non-significant, the model fit is mostly contributed by the constants. This is mainly caused by non-trading behavior which will be discussed later in detail.

For both one-way and roundtrip carsharing, Class 1 and 2 are labeled as "OwnershipOriented" and "CS-Oriented" according to their choice patterns. The choice responses are rather extreme for both classes: when answering whether to obtain or give up ownership of a current (or intended) car if carsharing becomes available, Class 1 choose to keep the 
car or go through the planned car purchase in over $97 \%$ of responses, while Class 2 opt for carsharing and forego the planned car purchase or replace one of their current cars in the vast majority (over $70 \%$ for one-way carsharing and $85 \%$ for roundtrip) of choice tasks. This implies that non-trading behavior is prevalent in the sample. Some research suggests that these observations shall be discarded (Hess et al. 2010) which can improve model fit (Wardman and Ibáñez 2012); however, it can be an expression of genuine preferences (Börjesson et al. 2012): given the attribute range in choice experiment design, when none of the other alternatives are more attractive than the alternative which the respondent sticks to, non-trading behavior is observed.

Comparing the two models, Class 1 takes a dominant share in both models $(78.3 \%$ and $82.5 \%$ ); while Class 2 of one-way carsharing (21.7\%) is slightly larger in size than that of roundtrip carsharing (17.5\%). The model results therefore suggest that the potential of both types of carsharing in reducing car ownership is on par with each other.

Now we briefly discuss the taste parameter for service attributes. The fuel type of the shared car does not have any significant impact on the final choice for both classes under both one-way and roundtrip carsharing. Except for the registration fee of one-way carsharing, none of the taste parameters for carsharing system attributes are significant for Class 2 , while access time is significant for Class 1 both for roundtrip and one-way carsharing. In addition, monthly membership cost and car availability also have significant impact under roundtrip carsharing. Similar to the trip replacement model, these non-significant parameters may be a true reflection of people's preferences: when considering whether to use carsharing and forego a planned car purchase (or shed an owned car), carsharing system attributes genuinely do not play an important role as long as they are not extremely high or low. It may also be explained by two other reasons: first, Class 1 hardly trade-off between attributes across choice tasks; second, the size of Class 2 is limited.

All variables with respect to the current (or expected) car (car price, fuel cost, maintenance cost and access time to one's own car) are significant for at least one class in the model for one-way or roundtrip carsharing. This implies that these factors influence the decision regarding whether to use carsharing and reduce car ownership. For Class 2 in both models, people who (are expected to) have a more expensive car are less likely to forego their ownership: this suggests that an expensive car may be more than a tool for transport and bears a symbolic value, which was revealed by previous studies (Steg 2005).

Several socio-economic variables account for preference heterogeneity (see Table 7). Both under roundtrip and one-way carsharing, employed people are more likely to be a member of Class 2. Under one-way carsharing, Class 2 is also younger. Gender, education, household composition, income are non-significant predictors for class membership in both models. There is no significant difference between the two classes regarding urban density distribution either. Although higher education and higher income can lead to a higher possibility to join and use carsharing, they are also found to have positive impact on the probability to maintain car ownership (Le Vine and Polak 2017), which may explain why their effects in our model become non-significant. In contrast, (Le Vine and Polak 2017) also found that people with children are more likely to join carsharing and reduce car ownership: although our Class 2 under one-way carsharing still has a much larger share of people with children, we do not find this strengthened impact. Under both one-way and roundtrip carsharing, people who are expected to buy a new car have a higher probability of belonging to Class 2 than those who do not. This was expected since the potential buyers are asked whether they will forego the planned purchase while the others answer whether they will shed a current car. It is certainly easier to give up a purchase which has not been materialized than giving up a car one already owns. 
Table 6 Parameters and z-values of the latent class discrete choice model regarding choice of car ownership

\begin{tabular}{|c|c|c|c|c|c|c|c|c|}
\hline & \multicolumn{4}{|l|}{ One-way } & \multicolumn{4}{|l|}{ Roundtrip } \\
\hline & \multicolumn{2}{|c|}{ Ownership-oriented } & \multicolumn{2}{|c|}{ CS-oriented } & \multicolumn{2}{|c|}{ Ownership-oriented } & \multicolumn{2}{|c|}{ CS-oriented } \\
\hline & Estimate & z-value & Estimate & z-value & Estimate & z-value & Estimate & z-value \\
\hline \multicolumn{9}{|c|}{ Alternative specific constant } \\
\hline Buy car & 0 & & 0 & & 0 & & 0 & \\
\hline Carsharing & -5.0970 & -4.0945 & 1.3890 & 1.2209 & -1.2586 & -1.4300 & 2.1376 & 4.6842 \\
\hline \multicolumn{9}{|l|}{ Attributes } \\
\hline Gasoline car & 0.1709 & 1.4110 & 0.1709 & 1.4110 & 0.0615 & 0.3990 & 0.0615 & 0.399 \\
\hline $\begin{array}{l}\mathrm{EV} \text { with } 100 \mathrm{~km} \\
\text { range }\end{array}$ & -0.1334 & -1.0610 & -0.1334 & -1.0610 & -0.0467 & -0.2952 & -0.0467 & -0.2952 \\
\hline $\begin{array}{l}\text { EV with } 200 \mathrm{~km} \\
\text { range }\end{array}$ & -0.0375 & -0.3088 & -0.0375 & -0.3088 & -0.0148 & -0.0999 & -0.0148 & -0.0999 \\
\hline Registration fee & -0.0130 & -2.3194 & -0.0130 & -2.3194 & & & & \\
\hline Deposit & & & & & -0.0004 & -0.6359 & -0.0004 & -0.6359 \\
\hline Membership cost & -0.0010 & -0.0516 & -0.001 & -0.0516 & -0.0443 & -2.5986 & 0.0219 & 1.2260 \\
\hline Minute cost & 2.6725 & 1.2711 & 2.6725 & 1.2711 & & & & \\
\hline Distance cost $/ \mathrm{km}$ & & & & & -0.7843 & -0.3159 & -0.7843 & -0.3159 \\
\hline Hour cost & & & & & -0.0842 & -1.3943 & -0.0842 & -1.3943 \\
\hline Availability & 0.7878 & 0.7706 & 0.7878 & 0.7706 & & & & \\
\hline $\begin{array}{l}\text { Difference from } \\
\text { ideal time }\end{array}$ & & & & & -0.0295 & -2.7693 & 0.0086 & 0.7470 \\
\hline Access time & -0.1703 & -2.6912 & -0.0208 & -0.8580 & -0.1115 & -3.0738 & 0.0144 & 0.4104 \\
\hline $\begin{array}{l}\text { Flexible return } \\
\text { location }\end{array}$ & 0.0177 & 0.1077 & 0.0177 & 0.1077 & & & & \\
\hline \multicolumn{9}{|c|}{ Current/expected car characteristics } \\
\hline Car price & 0.0162 & 1.1668 & -0.0471 & -4.2881 & -0.0032 & -0.3117 & -0.0191 & -3.4387 \\
\hline Fuel cost & 0.3208 & 0.1386 & -0.6997 & -0.9110 & 0.0105 & 0.3134 & -0.1114 & -2.6893 \\
\hline Parking distance & 0.2334 & 8.4361 & -0.0515 & -3.7330 & 2.0985 & 1.4541 & 5.4214 & 2.8559 \\
\hline Maintenance cost & -0.0024 & -3.2154 & -0.0003 & -0.4654 & -0.0024 & -1.5916 & -0.0008 & -0.7355 \\
\hline Log-likelihood & -730 & & & & -674 & & & \\
\hline Null log-likelihood & -2166 & & & & -2004 & & & \\
\hline $\begin{array}{l}\text { McFadden rho- } \\
\text { square }\end{array}$ & 0.663 & & & & 0.664 & & & \\
\hline $\begin{array}{l}\text { Log-likelihood of } \\
\text { MNL }\end{array}$ & -1407 & & & & -1336 & & & \\
\hline
\end{tabular}

People's travel patterns also have substantial influence on class membership. Class 2 has more frequent public transport users under one-way carsharing and contains more intensive bike users under roundtrip carsharing. This suggests that a multi-modal person is more likely to forego car ownership when carsharing becomes available.

Of the three attitudinal items, only the hedonic attitude has a significant effect on class membership, which shows that the decision of giving up car ownership is influenced by the individual's attachment to car ownership, while one's perception regarding the environmental friendliness and symbolic image of carsharing do not have much impact. 


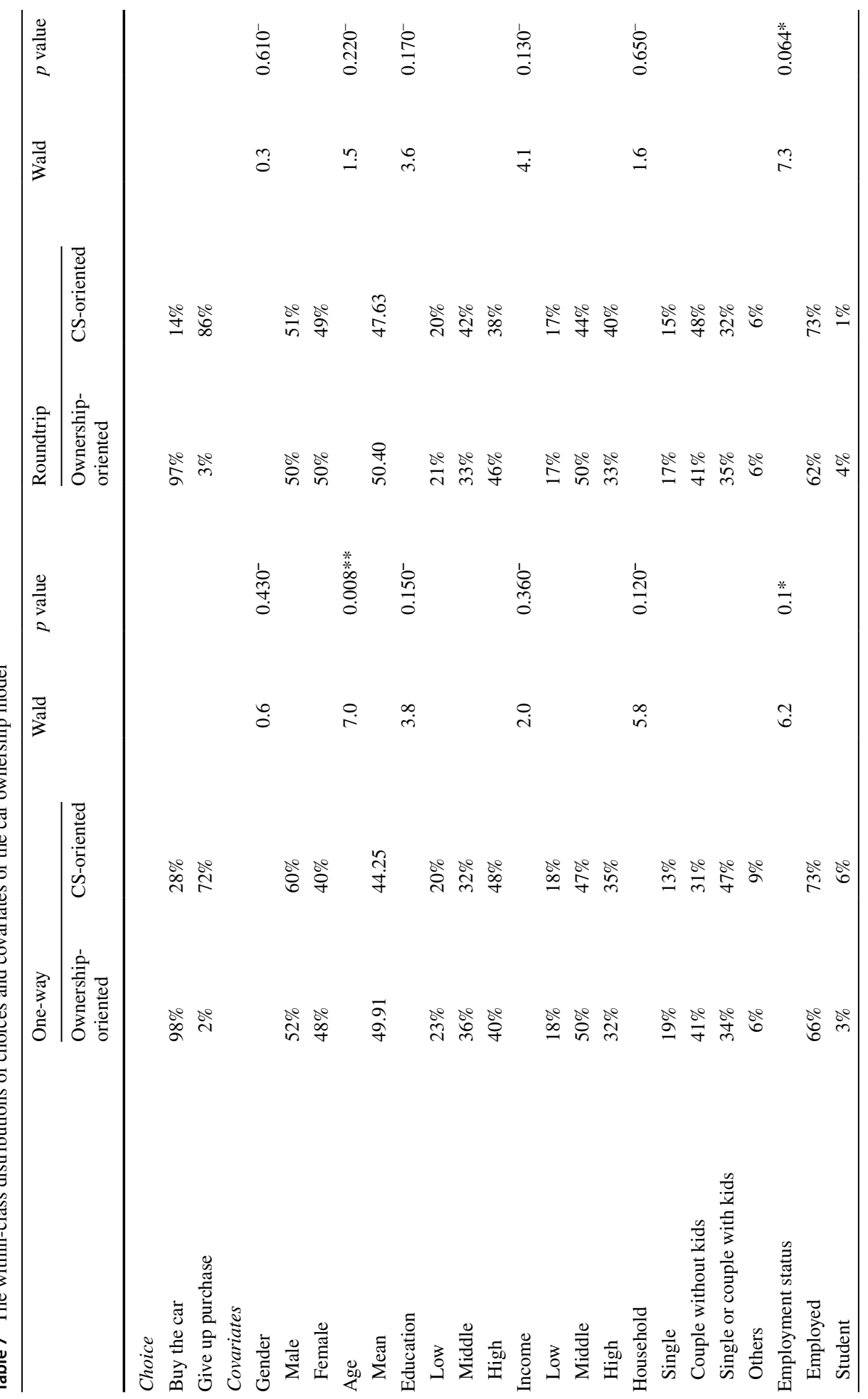




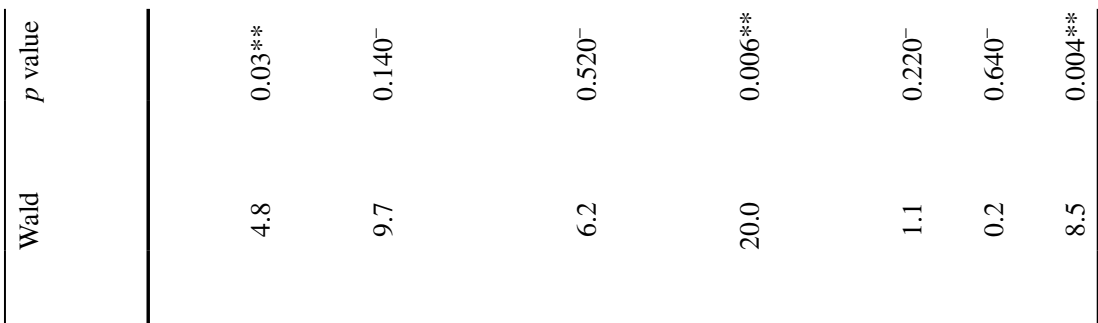

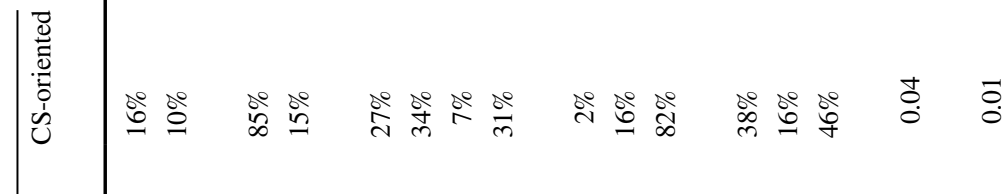

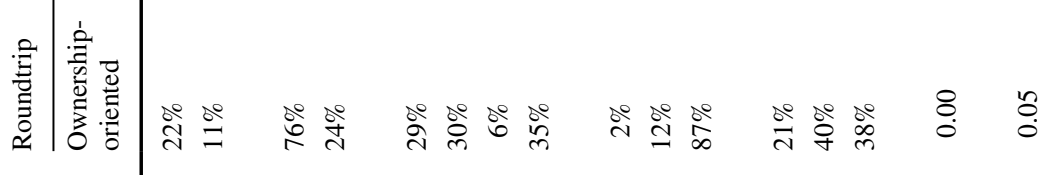

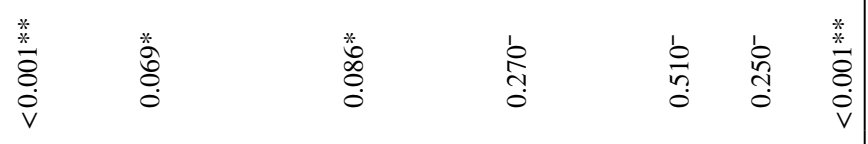

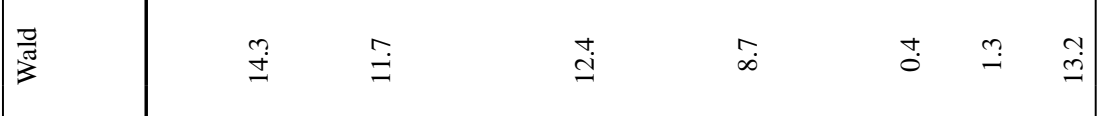

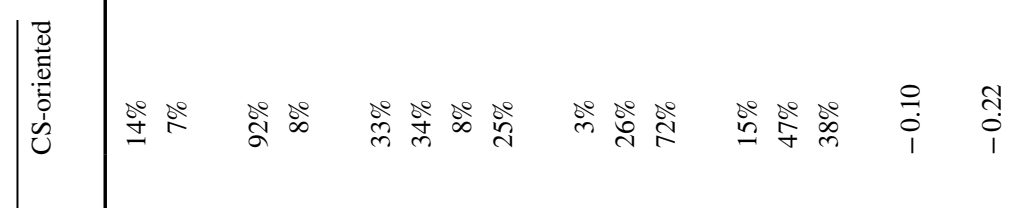

$$
\begin{aligned}
& \text { 空高离 }
\end{aligned}
$$

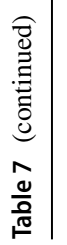

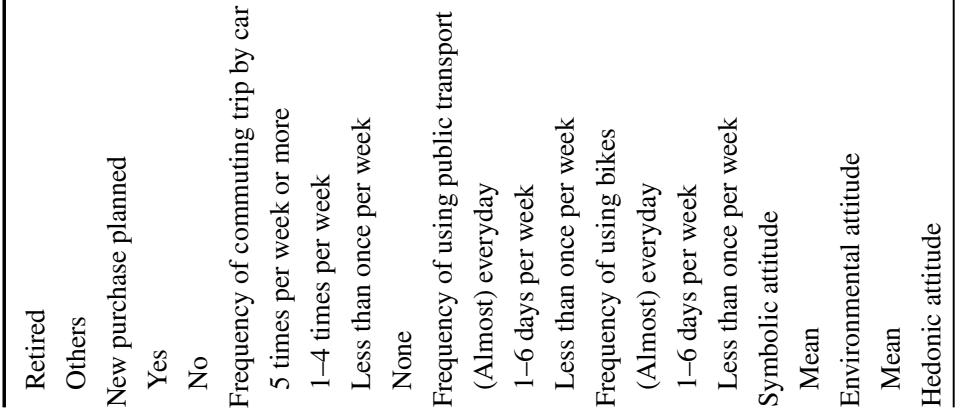




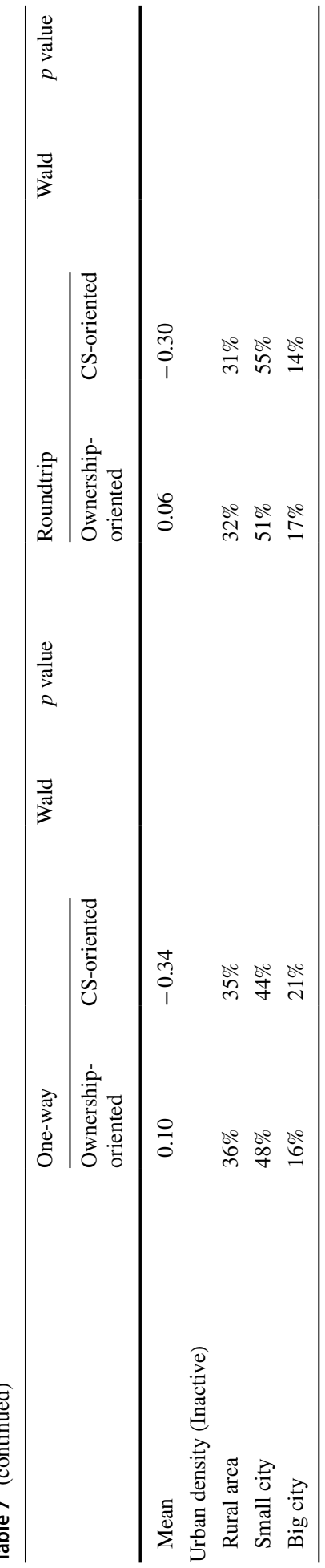




\section{Relation between the trip replacement and car ownership decisions}

A main motivation for car ownership is to conduct trips by car. If carsharing becomes available and can also fulfill this functional use of car ownership, it is likely to reduce the need for car ownership. Therefore, a plausible conjecture is that the intention of reducing car ownership is related to people's willingness to replace their private car trips by carsharing. In electric vehicle adoption research, several studies assume that the acceptance of $\mathrm{EV}$ is strongly related to the inconvenience caused by EV which stems from the mismatch of the limited driving range of EV and the travel pattern (such as long trips) of individuals (Tamor et al. 2015; Tamor et al. 2013). Similarly, as we mentioned in the introduction, there have been previous research effort to measure the potential of carsharing by calculating how many people's current travel patterns are economically compatible with carsharing (Duncan 2011; Schuster et al. 2005): the inherent assumption is that the choice of giving up car ownership depends on the extent to which carsharing can cover (replace) one's current trips. In this section, we aim to investigate whether people who intend to use carsharing to replace more of their private car trips are more willing to give away (one of) their car.

We assign each respondent to a class in both classifications (trip replacement and car ownership) according to the posterior probabilities of belong to a particular class based on their responses and individual characteristics, and explore whether there is any relation between these two class memberships. Tables 8 and 9 display the cross tables of people's membership under the two classifications for one-way and roundtrip carsharing. We can derive some interesting insights from the two tables:

(1) Some people who choose carsharing to replace very few of their car trips are still willing to give up their car ownership, albeit the share is rather small (10\% of the total sample). A possible explanation for this may be that only a small share of the current car trips absolutely needs to be done by driving; with the support of carsharing in fulfilling this essential need, this group can shed a car and turn to other travel modes such as biking or public transport to conduct the trips which were previously conducted by private car. This group therefore may correspond to those carsharing users who reduced their mileage of car trips after joining carsharing scheme and give up their car (Millard-Ball et al. 2005).

(2) In the case of one-way carsharing, the preference regarding trip replacement is in line with their preference for giving up car ownership: CS-enthusiasts has the largest percentage which are CS-oriented than other two groups. Le Vine and Polak (2017) also found that those who use free-floating carsharing more are also more likely to reduce their car ownership.

(3) In the model of roundtrip carsharing, the percentage of CS-enthusiasts (Class 3 in the trip replacement decision) who are also CS-oriented (Class 2 in the car ownership decision) is lower than CS-leaning (Class 2 in the trip replacement decision). This may seem surprising since CS-enthusiasts on average are willing to use carsharing to replace more of their private car trips than CS-leaning. However, in Table 5 we can see that the CS-leaning class of roundtrip carsharing has the lowest hedonic score which indicates their low attachment to their own car compared to the other two groups. This shows that the decision of reducing car ownership does not solely depend on the practical consideration such as how many current trips can the carsharing scheme serve. 
Other factors may override the importance of the practicalities, such as emotions and attachment towards car ownership.

It is expected that one-way free-floating carsharing is the most popular scheme due to its flexibility comparing to one-way station-based and roundtrip carsharing. Our results show that indeed a larger group of car drivers is interested in using one-way carsharing for some of their car trips compared to roundtrip; however, one-way carsharing does not show significantly higher potential in reducing car ownership. The relation between usage intensity and car ownership reduction is also different for the two types of carsharing systems. Furthermore, the perks of free-floating carsharing - free parking at all public parking spotsdo not show any effect on the probability of joining or using carsharing. We expect carsharing (especially one-way) is most likely to be operated within big cities with a certain level of urban density to be profitable. People living in highly urbanized areas may also have a higher interest in carsharing due to the limited parking and expensive parking fee in these areas. However, we discerned no significant difference in the overall preferences for carsharing between people living in areas with different levels of urban density (the urban density level variable is non-significant in the membership function).

\section{Conclusions and discussion}

\section{Conclusion}

This study aims to investigate car drivers' intention of replacing private car trips by carsharing and reducing car ownership when a carsharing scheme is available, which shed light on the potential of carsharing among all car drivers. Latent class models are estimated to identify groups with different preference profiles. We found that for both intentions of trip replacement and car ownership reduction, people vary significantly with respect to their preferences for carsharing in general, its system attributes and how the characteristics of their own car affect their preferences. In total around $40 \%$ of the entire sample (CSleaning and CS-enthusiasts) indicate that they may be willing to use carsharing to replace at least some of their private car trips. About $20 \%$ (CS-oriented) are likely to give up a planned car purchase or shed a current car when a suitable carsharing system becomes available. These numbers can be regarded as an upper limit of the potential for carsharing in replacing private car trips and reducing car ownership since models calibrated by stated preference data tend to overrate the preference for new products (see "Limitations and recommendations for research" section). This variance of preference may be attributed to the difference in socio-economic condition, travel pattern and carsharing-related attitudes, confirming similar findings in previous studies.

We also examined the impact of carsharing system attributes on these two intentions. As for the fuel type of the shared cars, it does not make any difference in the decision of giving up car ownership. Regarding the trip replacement decision, EVs are even preferred to gasoline vehicles by some classes; however, EVs with limited range is less preferred when carsharing is mostly used for long trips, but a driving range of $200 \mathrm{~km}$ is enough to compensate in this case. Based on these findings we may conclude that consumers in general do not show resistance and even demonstrate preference for electric vehicles. Regarding other system attributes such as costs and availability, if the current performance level is already acceptable (within the range of our experiment), a further improvement of the 
Table 8 The distribution within the two classifications for one-way carsharing

\begin{tabular}{lllllc}
\hline Car model class & Trip model class & $\begin{array}{l}\text { Own-car } \\
\text { oriented } \\
(\%)\end{array}$ & CS-leaning (\%) & $\begin{array}{l}\text { CS- } \\
\text { enthusi- } \\
\text { asts (\%) }\end{array}$ & Class size (\%) \\
\hline Ownership-oriented & \% within trip model class & 91.6 & 70.5 & 54.2 & 78.2 \\
CS-oriented & \% within trip model class & 8.5 & 29.5 & 45.8 & 21.8 \\
Class size & \% of total & 54.7 & 24.8 & 20.5 & 100.0 \\
\hline
\end{tabular}

Table 9 The distribution within the two classifications for roundtrip carsharing

\begin{tabular}{llllll}
\hline Car model class & Trip model class & $\begin{array}{l}\text { Own-car } \\
\text { oriented } \\
(\%)\end{array}$ & CS-leaning (\%) & $\begin{array}{l}\text { CS- } \\
\text { enthusi- } \\
\text { asts }(\%)\end{array}$ & Car class size (\%) \\
\hline Onwership-oriented & $\begin{array}{l}\text { \% within trip model } \\
\text { class }\end{array}$ & 89.5 & 67.0 & 76.1 & 82.5 \\
CS-oriented & $\begin{array}{l}\text { \% within trip model } \\
\text { class } \\
\text { \% of total }\end{array}$ & 10.5 & 33.0 & 23.9 & 17.5 \\
Trip class size & 63.4 & 22.7 & 13.9 & 100.0 \\
\hline
\end{tabular}

system performance in these aspects do not seem to have a significant impact on facilitating carsharing to replace car ownership or private car trips.

As for the relation between the decision of trip replacement and forgoing car ownership, people who use carsharing to replace more trips are not necessarily more willing to give up their car, which indicates that these two effects of carsharing must be studied separately. By looking at the two decisions together, we arrive at a more detailed classification of the population and a richer picture of people's preference profiles regarding carsharing. We reveal groups such as heavy carsharing users who still want the guarantee of their own car and people who are willing to give up their car even when carsharing cannot replace most of their car trips (which they may conduct by other travel modes instead).

\section{Policy implications}

We can derive several policy implications from the findings. First, our study reveals that the potential for car sharing is quite large: as explained above $40 \%$ of the entire sample indicate that they may be willing to use carsharing to replace at least some of their private car trips, and $20 \%$ are likely to give up a planned car purchase or shed a current car when a suitable carsharing system becomes available. This implies that policies stimulating car sharing can have substantial societal relevant advantages, related to owning and using cars, as explained in the introduction. Policies to stimulate car sharing can, for example, be the provision of designated parking facilities (pull) but also the introduction of more paid parking in residential areas (push). Secondly, deploying electric vehicles has no negative or even slightly positive impact on increasing carsharing use, which confirms the potential of carsharing in reducing car trip emissions. This not only is relevant because shared vehicles can be EVs reducing the environmental pressure of car use, but it is also relevant because an increase in EV sales in the fleets of shared vehicles can stimulate EV sales in the entire 
car fleet, because due to scale effects (more sales) prices of EVs will go down, and the relatively high purchase costs are a barrier for many people to buy an EV (Liao et al. 2017). Thirdly, the potential of CS to reduce car ownership reduces the environmental impact of car ownership — note that producing cars also results in environmental pressure. And parking pressure can to some extent be reduced via increased levels of sharing. So, policies that stimulate CS might have environmental benefits via reduced ownership levels. Fourth, for one-way carsharing systems, in contrast to station-based setting, free-floating setting usually require much more government cooperation since it demands access to public parking spots. However, our results suggest that consumers do not really appreciate the extra flexibility brought by free-floating. This suggests that a station-based one-way carsharing system (such as Autolib in Paris) is a better option which is easier to implement and does not reduce utility for its users. Fifth, reducing user costs or increasing the availability of shared cars seem to have little or no impact on mid-term decisions such as the extent of replacing private car trips and reducing car ownership. Therefore, these strategies are probably not useful if the goal is to facilitate more trip replacement and car ownership reduction. Sixth, our results reveal that potential consumers' preferences regarding carsharing are highly heterogeneous. Certain groups have more favorable attitudes and preferences towards carsharing and may be more susceptible to carsharing promotion policies/strategies, thus it is recommended that they are given higher priority in such promotion. Furthermore, since the groups which intend to use carsharing to replace more private car trips do not necessarily overlap with the group which is more willing to reduce car ownership, campaigns and advertisements promoting carsharing should choose target groups depending on their specific goal. Seventh, because our study shows that young people are more than average inclined to become users of CS systems, such systems may lead to postponed car ownership, or even to an overall reduction of the desirability of owning a car, as debated in the literature on 'peak car' (Goodwin and van Dender 2013).

\section{Limitations and recommendations for research}

This study has several limitations. First, since carsharing is still a niche market, despite the fact that we collected a sample of average size, the number of respondents who are potentially interested in carsharing is rather limited; we also observed the prevalence of non-trading behavior among the general population. This may lead to statistical insignificance of some attributes, predictors and covariates. If we wish to have better estimates of the preference coefficients of the potentially interested group in order to fine tune the carsharing scheme services, we need a sample which is more targeted towards the potentially interested customers. However, this was not the main aim of this study, which was to examine the potential of carsharing among the general population of car drivers. Second, stated preference method is known to result in inflated willingness-to-pay for some socially desirable behaviors (Axsen et al. 2015), and the online survey we used for data collection is known to result in even more positive responses than other types of surveys such as faceto-face interviews (Efthymiou and Antoniou 2016). Therefore, our results may be overoptimistic in evaluating the potential of carsharing. Thus, while we find that the carsharing potential is rather limited in the general car driver population, it may even be more limited than we find here. Third, in this explorative study we simplified some aspects of the choice problems: for example, we did not consider the uncertainty of remaining range when someone takes an electric shared car with limited range. Neither did we consider more flexible pricing structure (such as different price for driving and parking). Finally, a large part of 
our respondents resides in rural areas. Although they seem to have no significant difference in terms of the intention of trip replacement and car ownership reduction and a fair share of them seem to be quite positive towards carsharing, it shall be kept in mind that some of the service attribute levels we used in the experiment are not economically feasible to be realized in those areas.

More future research is needed in order to better investigate people's preferences and the possible benefits of all types of carsharing. Comparing the usage pattern of roundtrip and one-way carsharing is an interesting direction which is of high practical relevance. For example, if one-way carsharing scheme is especially often used for shopping trips, then the carsharing scheme can set up more stations (parking docks) around shopping centers. The potential of peer-to-peer (P2P) carsharing in rural area is also worth investigating: our results show that people living in rural area seem to be as interested in carsharing as people from urban areas; however, as we mentioned in the limitations, the carsharing systems in our experiment may not be feasible or profitable in rural area and $\mathrm{P} 2 \mathrm{P}$ carsharing may be the only option. Therefore, it is important to examine people's preference for P2P carsharing. Furthermore, if we wish to arrive at a more realistic forecast of the potential of carsharing, we may combine revealed preference data with stated choice data in the model estimation. Finally, the introduction of shared autonomous vehicles will also further complicate or even completely change the entire picture. Many researcher, planners and policy makers now envision a prospect in which car ownership is vastly reduced because people on a large scale will make use of shared autonomous cars. However, our results pose doubt on this prospect: most people prefer to remain owning a car and only intend to make limited use of carsharing to replace their trips, and this preference is not very sensitive to improvements of carsharing systems. It is more likely that as long as cars are affordable and parking regulations with respect to car parking do not dramatically change, people will continue to own and use private cars even when shared autonomous cars become available on a large scale. Therefore, more behavioral research is needed to investigate the feasibility and possibility of the rosy future scenario promised by the introduction of shared autonomous vehicles.

Acknowledgement We would like to thank the three anonymous reviewers for their helpful comments.

Authors' contribution FL conceived of the study, participated in experiment design, performed statistical analysis, drafted manuscript. EM helped shaping research design, participated in experiment design, extensively edited the manuscript. HT commented on experiment design, edited the manuscript. BW helped shaping research design, commented on experiment design, edited the manuscript.

\section{Compliance with ethical standards}

Conflict of interest All authors declare that they have no conflict of interest.

Open Access This article is distributed under the terms of the Creative Commons Attribution 4.0 International License (http://creativecommons.org/licenses/by/4.0/), which permits unrestricted use, distribution, and reproduction in any medium, provided you give appropriate credit to the original author(s) and the source, provide a link to the Creative Commons license, and indicate if changes were made.

\section{References}

Agresti, A.: Categorical Data Analysis. Wiley, New York (2002) 
Axsen, J., Bailey, J., Castro, M.A.: Preference and lifestyle heterogeneity among potential plug-in electric vehicle buyers. Energy Econ. 50, 190-201 (2015). https://doi.org/10.1016/j.eneco.2015.05.003

Becker, H., Ciari, F., Axhausen, K.W.: Comparing car-sharing schemes in Switzerland: user groups and usage patterns. Transp. Res. Part A Policy Pract. 97, 17-29 (2017). https://doi.org/10.1016/j. tra.2017.01.004

Bergkvist, L., Rossiter, J.R.: The predictive validity of multiple-item versus single-item measures of the same constructs. J. Mark. Res. 44, 175-184 (2007). https://doi.org/10.1509/jmkr.44.2.175

Bert, J., Collie, B., Gerrits, M., Xu, G.: What's ahead for car sharing? The new mobility and its impact on vehicle sales. Boston Consulting Group. 23 February 2016. Available online: https://www.bcg.com/ publications/2016/automotive-whats-ahead-car-sharing-new-mobility-its-impact-vehicle-sales.aspx (2016). Accessed 9 Oct 2018

Börjesson, M., Fosgerau, M., Algers, S.: Catching the tail: empirical identification of the distribution of the value of travel time. Transp. Res. Part A Policy Pract. 46, 378-391 (2012). https://doi.org/10.1016/j. tra.2011.10.006

Cartenì, A., Cascetta, E., de Luca, S.: A random utility model for park and carsharing services and the pure preference for electric vehicles. Transp. Policy 48, 49-59 (2016). https://doi.org/10.1016/j.tranp ol.2016.02.012

Cervero, R., Golub, A., Nee, B.: City carshare: longer-term travel demand and car ownership impacts. Transp. Res. Rec. J. Transp. Res. Board 1992, 70-80 (2007). https://doi.org/10.3141/1992-09

Ciari, F., Balac, M., Balmer, M.: Modelling the effect of different pricing schemes on free-floating carsharing travel demand: a test case for Zurich, Switzerland. Transp. (Amst) 42, 413-433 (2015). https://doi. org/10.1007/s11116-015-9608-z

De Luca, S., Di Pace, R.: Modelling the propensity in adhering to a carsharing system: a behavioral approach. Transp. Res. Procedia 3, 866-875 (2014). https://doi.org/10.1016/j.trpro.2014.10.065

Douma, F., Gaug, R.: Carsharing in the twin cities: measuring impacts on travel behavior and automobile ownership. In: 88th Annual Meeting of the Transportation Research Board, Washington D.C. (2009)

Duncan, M.: The cost saving potential of carsharing in a US context. Transp. (Amst) 38, 363-382 (2011). https://doi.org/10.1007/s11116-010-9304-y

Efthymiou, D., Antoniou, C.: Modeling the propensity to join carsharing using hybrid choice models and mixed survey data. Transp. Policy (2016). https://doi.org/10.1016/j.tranpol.2016.07.001

Efthymiou, D., Antoniou, C., Waddell, P.: Factors affecting the adoption of vehicle sharing systems by young drivers. Transp. Policy 29, 64-73 (2013). https://doi.org/10.1016/j.tranpol.2013.04.009

Firnkorn, J., Müller, M.: What will be the environmental effects of new free-floating car-sharing systems? The case of car2go in Ulm. Ecol. Econ. 70, 1519-1528 (2011). https://doi.org/10.1016/j. ecolecon.2011.03.014

Firnkorn, J., Müller, M.: Free-floating electric carsharing-fleets in smart cities: the dawning of a post-private car era in urban environments? Environ. Sci. Policy 45, 30-40 (2015). https://doi. org/10.1016/j.envsci.2014.09.005

Goodwin, P., van Dender, K.: "Peak car"-themes and issues. Transp. Rev. 33, 243-254 (2013). https:// doi.org/10.1080/01441647.2013.804133

Harms, L., Jorritsma, P., Berveling, J., Meerkerk, J. Van, Nijland, H.: Carsharing in the Netherlands : user characteristics and mobility effects. In: 14th World Conference on Transport Research (WCTR), Shanghai (2016)

Hess, S., Rose, J.M., Polak, J.: Non-trading, lexicographic and inconsistent behaviour in stated choice data. Transp. Res. Part D Transp. Environ. 15, $405-417$ (2010). https://doi.org/10.1016/j. trd.2010.04.008

Juschten, M., Ohnmacht, T., Thao, V.T., Gerike, R., Hössinger, R.: Carsharing in Switzerland: identifying new markets by predicting membership based on data on supply and demand. Transp. (Amst) (2017). https://doi.org/10.1007/s11116-017-9818-7

Kato, H., Inagi, A., Igo, T.: Awareness and potential choices of carsharing: comparative analysis of data from four Japanese cities. In: Proceedings of the 91st Annual Meeting of the Transportation Research Board, Washington D.C. (2012)

Kim, D., Ko, J., Park, Y.: Factors affecting electric vehicle sharing program participants' attitudes about car ownership and program participation. Transp. Res. Part D Transp. Environ. 36, 96-106 (2015). https://doi.org/10.1016/j.trd.2015.02.009

Kim, J., Rasouli, S., Timmermans, H.: Satisfaction and uncertainty in car-sharing decisions: an integration of hybrid choice and random regret-based models. Transp. Res. Part A Policy Pract. 95, 13-33 (2017a). https://doi.org/10.1016/j.tra.2016.11.005 
Kim, J., Rasouli, S., Timmermans, H.J.P.: The effects of activity-travel context and individual attitudes on car-sharing decisions under travel time uncertainty: a hybrid choice modeling approach. Transp. Res. Part D Transp. Environ. 56, 189-202 (2017b). https://doi.org/10.1016/j.trd.2017.07.022

Klincevicius, M.G.Y., Morency, C., Trépanier, M.: Assessing impact of carsharing on household car ownership in Montreal, Quebec, Canada. Transp. Res. Rec. J. Transp. Res. Board 2416, 48-55 (2014). https://doi.org/10.3141/2416-06

Le Vine, S., Polak, J.: The impact of free-floating carsharing on car ownership: early-stage findings from London. Transp. Policy (2017). https://doi.org/10.1016/j.tranpol.2017.02.004

Le Vine, S., Adamou, O., Polak, J.: Predicting new forms of activity/mobility patterns enabled by shared-mobility services through a needs-based stated-response method: case study of grocery shopping. Transp. Policy. 32, 60-68 (2014a). https://doi.org/10.1016/j.tranpol.2013.12.008

Le Vine, S., Lee-Gosselin, M., Sivakumar, A., Polak, J.: A new approach to predict the market and impacts of round-trip and point-to-point carsharing systems: case study of London. Transp. Res. Part D Transp. Environ. 32, 218-229 (2014b). https://doi.org/10.1016/j.trd.2014.07.005

Liao, F., Molin, E., van Wee, B.: Consumer preferences for electric vehicles: a literature review. Transp. Rev. 37, 252-275 (2017). https://doi.org/10.1080/01441647.2016.1230794

Martin, E., Shaheen, S., Lidicker, J.: The impact of carsharing on household vehicle ownership. Transp. Res. Rec. J. Transp. Res. Board 2143, 150-158 (2010)

Millard-Ball, A., Murray, G., Schure, J. Ter, Fox, C., Burkhardt, J.: Car-Sharing: Where and How it Succeeds, TCRP Report, Washington D.C. (2005)

Rose, J.M., Bliemer, M.C.J.: Constructing efficient stated choice experimental designs. Transp. Rev. 29, 587-617 (2009). https://doi.org/10.1080/01441640902827623

Rotaris, L., Danielis, R.: The role for carsharing in medium to small-sized towns and in less-densely populated rural areas. Transp. Res. Part A Policy Pract. (2017). https://doi.org/10.1016/j.tra.2017.07.006

Schuster, T., Byrne, J., Corbett, J., Schreuder, Y.: Assessing the potential extent of carsharing: a new method and its implications. Transp. Res. Rec. J. Transp. Res. Board 1927, 174-181 (2005). https:// doi.org/10.3141/1927-20

Shaheen, S.A., Cohen, A.P.: Carsharing and personal vehicle services: worldwide market developments and emerging trends. Int. J. Sustain. Transp. 7, 5-34 (2013). https://doi.org/10.1080/15568 318.2012.660103

Shankar, G., Clewlow, R.R., Mokhtarian, P.L., Widaman, K.F.: The effect of carsharing on vehicle holdings and travel behavior: a propensity score and causal mediation analysis of the San Francisco Bay Area. Res. Transp. Econ. (2015). https://doi.org/10.1016/j.retrec.2015.10.010

Steg, L.: Car use: lust and must. Instrumental, symbolic and affective motives for car use. Transp. Res. Part A Policy Pract. 39, 147-162 (2005). https://doi.org/10.1016/j.tra.2004.07.001

Tal, G.: Evaluating the effect of car-sharing: exploring the gap between what we know vs. what we need to know and its effect on optimism bias. In: Transportation Research Board 88th Annual Meeting (2009)

Tamor, M.A., Gearhart, C., Soto, C.: A statistical approach to estimating acceptance of electric vehicles and electrification of personal transportation. Transp. Res. Part C Emerg. Technol. 26, 125-134 (2013). https://doi.org/10.1016/j.trc.2012.07.007

Tamor, M.A., Moraal, P.E., Reprogle, B., Milačić, M.: Rapid estimation of electric vehicle acceptance using a general description of driving patterns. Transp. Res. Part C Emerg. Technol. 51, 136-148 (2015). https://doi.org/10.1016/j.trc.2014.10.010

Vermunt, J.K., Magidson, J.: Technical guide for Latent GOLD 5.0: Basic, advanced, and syntax. Statistical Innovations Inc, Belmont, MA (2013)

Wardman, M., Ibáñez, J.N.: The congestion multiplier: variations in motorists' valuations of travel time with traffic conditions. Transp. Res. Part A Policy Pract. 46, 213-225 (2012). https://doi.org/10.1016/j. tra.2011.06.011

Zhou, B., Kockelman, K.M.: Opportunities for and impacts of carsharing: a survey of the Austin, Texas market. Int. J. Sustain. Transp. 5, 135-152 (2011). https://doi.org/10.1080/15568311003717181

Zoepf, S.M., Keith, D.R.: User decision-making and technology choices in the U.S. carsharing market. Transp. Policy (2016). https://doi.org/10.1016/j.tranpol.2016.01.010

Fanchao Liao is a Ph.D. candidate in the Transport and Logistics section at Delft University of Technology. Her main research interests lie in modeling decision-making behavior.

Eric Molin is an associate professor of Travel Behavior Research at Delft University of Technology. He received a Ph.D. degree at Eindhoven University of Technology and a Masters of Arts degree in Sociology at Radboud University Nijmegen, with a specialization in social research methods. He specialized in 
developing advanced stated choice experiments. Topics of research involve travelers' preferences regarding multi-modal transport systems and innovative transport technologies, in particular travel information services, alternative fueled vehicles and automated driving.

Harry Timmermans is Head of the Urban Planning Group of the Eindhoven University of Technology, the Netherlands. He has research interests in modeling decision-making processes and decision support systems in a variety of application domains, including transportation. He is editor of the Journal of Retailing and Consumer Services, and serves on the board of several other journals in transportation, geography, urban planning, marketing, artificial intelligence and other disciplines. He is Co-chair of the International Association of Travel Behavior Research (IATBR), and member of several scientific committees of the Transportation Research Board. He has also served as member of conference committees in transportation and artificial intelligence.

Bert van Wee is professor in Transport Policy at Delft University of Technology, the Netherlands, faculty Technology, Policy and Management. In addition, he is scientific director of TRAIL research school. His main interests are in long-term developments in transport, in particular in the areas of accessibility, land-use transport interaction, (evaluation of) large infrastructure projects, the environment, safety, policy analyses and ethics. 